Romero Vera, D., (2020): “Consideraciones sobre la arquitectura doméstica urbana de Hispania en el siglo II d.C.", Spal 29.1: 243-270.

DOI: http://dx.doi.org/10.12795/spal.2020.i29.09

\title{
CONSIDERACIONES SOBRE LA ARQUITECTURA DOMÉSTICA URBANA DE HISPANIA EN EL SIGLO II D.C.
}

\section{CONSIDERATIONS ON THE DOMESTIC ARCHITECTURE OF HISPANIA IN THE SECOND CENTURY AD}

\author{
DIEGO ROMERO VERA \\ Departamento de Prehistoria y Arqueología \\ Facultad de Geografía e Historia. Universidad de Sevilla. C/ Doña María de Padilla, S/N, 41004 - Sevilla \\ Correo-e: drvera@us.es. (D) https://orcid.org/0000-0002-4562-2407 \\ Researcher ID: <https://publons.com/researcher/AAE-9894-2019
}

Resumen: En este trabajo ofrecemos una revisión sintética de las evidencias arqueológicas pertenecientes a domus del siglo II d.C. que han ofrecido una veintena de núcleos urbanos de Hispania. Partiendo de esta documentación, pretendemos establecer un primer acercamiento a los rasgos característicos de la arquitectura doméstica hispanorromana en esta época.

Palabras clave: Domus, época antonina, ciudades hispanorromanas, balnea, monumentalización, crisis urbana.

\section{INTRODUCCIÓN}

En el presente artículo abordamos una aproximación a las principales dinámicas y características que rigen la arquitectura residencial de un nutrido grupo de ciudades hispanorromanas en el siglo II d.C. Somos conscientes de la dificultad que entraña ofrecer una visión integradora sobre este tema en un marco temporal tan amplio y del que, además, existe una enorme (y muy
Abstract: In this work we will review briefly the domestic archeological evidence dated in the second century belonging to a score of Hispania's urban centres. On the basis of this documentation, we would like to offer, in general terms, the characteristic features of the hispanorroman domestic architecture in this period.

Keywords: Domus, Antonine epoch, Hispano-Roman cities, balnea, monumentalization, urban crisis

dispar en cuanto a su calidad) documentación. Como vemos, el objetivo planteado no resulta nada sencillo.

Asimismo, creemos que se trata de una investigación pertinente y necesaria por varias razones: por un lado, pese a la gran cantidad de evidencias aportada por el registro arqueológico y al impulso que ha recibido el estudio de la vivienda hispanorromana en las últimas décadas, todavía existen importantes lagunas en este campo de investigación. 
En efecto, la atención de los investigadores se ha centrado preferentemente en la decoración y los modelos arquitectónicos. Tampoco hay que pasar por alto que la gran mayoría de las intervenciones realizadas en yacimientos no superpuestos se concentran en los espacios públicos de la ciudad, quedando sin excavar la mayor parte del núcleo urbano, compuesto justo por aquellas áreas que fueron ocupadas previsiblemente por viviendas. Por su parte, en las llamadas ciudades superpuestas o históricas, las casas no siempre son excavadas en extensión debido a la complicada naturaleza de las intervenciones arqueológicas en contexto urbano. Todos estos factores determinan el estado actual de conocimiento sobre la vivienda hispanorromana.

En general, los estudios de conjunto sobre la vivienda romana en la península ibérica son muy escasos (Balil 1972, A.A.V.V. 1991, Beltrán y Mostalac 1996, Gros 2001: 137 y ss., Beltrán 2003). Concretamente, no existe una obra actualizada que arroje una visión global sobre el tema propuesto; sin embargo, sí se han publicado ciertos estados de la cuestión sobre la casa hispanorromana que presentan una somera evolución de la edilicia doméstica desde época tardorrepublicana hasta el final de la Antigüedad (Beltrán y Mostalac 1996, Beltrán 2003). Por lo común, los estudios de este género se han centrado en unidades residenciales concretas o en análisis de la arquitectura doméstica de determinados núcleos urbanos. Con todo, en fecha reciente se han realizado estudios que dejan atrás la perspectiva local para analizar esta materia en áreas precisas de la península ibérica (Rodríguez Gómez 2010, Bermejo 2014, Cortés 2014b, Uribe 2015).

En lo que respecta al análisis de las diferentes etapas evolutivas de la casa hispanorromana, se echa en falta, especialmente, un estudio sincrónico sobre la edilicia doméstica en época antonina, periodo que con toda seguridad (y especialmente en lo que respecta a la decoración) fue uno de los de mayor esplendor de la vivienda hispanorromana (Ramallo 1990: 141-160, Pérez Olmedo 1996: 42-49, Beltrán y Mostalac 1996: 68, Beltrán 2003: 50-51, López Monteagudo 2003: 301333, Garriguet 2013: 266 y ss., Fernández Díaz 2014: 209-216). En efecto, el registro arqueológico revela que muchas casas adquirieron su configuración definitiva (al menos desde el punto de vista ornamental) o fueron construidas en este periodo. Este aspecto resulta especialmente llamativo si tenemos en cuenta que en Hispania las construcciones públicas disminuyen a partir de la segunda mitad del siglo II d.C. Todo indica que las ciudades hispanorromanas vivieron en época antonina una fase de cierto estatismo, tras haberse dotado de las infraestructuras y los edificios públicos necesarios en las etapas precedentes. En efecto, en los espacios públicos, la dedicación de epígrafes se fue reduciendo $\mathrm{y}$, aunque se detectan algunas intervenciones decorativas y constructivas, su volumen decae abruptamente con respecto al periodo anterior (Romero Vera 2016: 374-383). Esto contrasta con la marcada luxuria privata que parece proyectarse en el ámbito doméstico, lo que induce a especular con un probable traslado de la inversión pública a la esfera privada en la Hispania del siglo II d.C. A esto cabría añadir que, desde finales de la segunda centuria, algunas poblaciones -no todasexperimentan un declive material que las llevará, en un breve periodo de tiempo, al colapso urbano. Nos estamos refiriendo, entre otras, a: Bilbilis (García Villalba y Sáenz 2015), Carthago Nova (Quevedo y Ramallo 2015), Emporiae (Castanyer et al. 1993), Labitolosa (Sillieres et al. 1995: 112), Lucentum (Guilabert et al. 2015); Iulia Lybica (Olesti et al. 2014), Dertosa (Járrega et al. 2014) Cartima (Berlanga y Melero 2009), Arucci/Turobriga (Bermejo 2011), Lesera (Arasa 2009: 81 y ss.), Torreparedones (Morena et al. 2011: $150 \mathrm{y}$ ss.), Tiermes (Pérez González et al. 2015: 250-251) y Los Bañales (Andreu et al. 2014).Precisamente, el análisis de la vivienda constituye un registro fiable para tasar el grado de vitalidad de las comunidades cívicas de época antonina y para evaluar, al mismo tiempo, la situación económica de sus habitantes.

En nuestro estudio hemos empleado el método comparativo a fin de establecer un primer acercamiento a los patrones o modelos que imperan en la arquitectura doméstica del citado marco cronológico-espacial. Con este objetivo, hemos analizado las evidencias correspondientes a un buen número de ciudades hispanorromanas, precisamente aquellas que ofrecen mayor cantidad de información arqueológica e histórica, en concreto: Astigi, Asturica Augusta, Augusta Emerita, Baelo Claudia, Baetulo, Barcino, Bilbilis, Bracara Augusta, Caesar Augusta, Carthago Nova, Clunia, Conimbriga, Corduba, Emporiae, Italica, Lucentum, Mirobriga Celticorum, Munigua, Saguntum, Segobriga, Tarraco y Valentia (fig. 1).

El catálogo está ordenado por provincias, disponiendo en primer término las capitales provinciales, después las capitales conventuales y, finalmente, el resto de ciudades. De esta forma, se tiene un acceso más razonable a la realidad de cada demarcación territorial de época romana, facilitando una valoración de conjunto de cada realidad provincial.

Somos conscientes de que este muestrario es limitado y no recoge todos los núcleos urbanos hispanos susceptibles de ofrecer información sobre arquitectura 


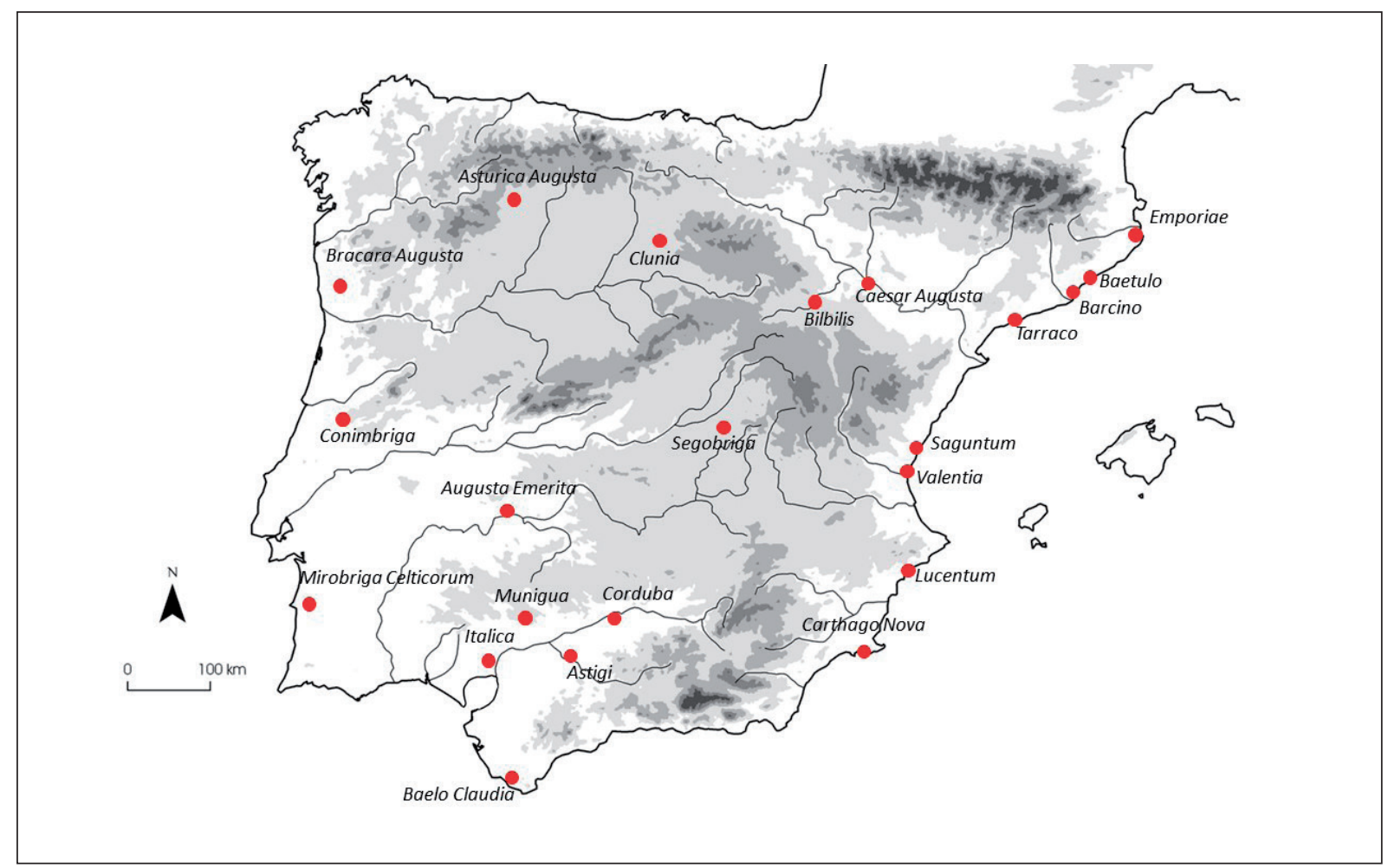

Figura 1. Situación de las ciudades hispanas analizadas en este trabajo.

doméstica. Sin embargo, estimamos que todas las ciudades analizadas son representativas y poseen un peso específico en este campo de estudio. Asimismo, el número de yacimientos que integran el catálogo, 22 en concreto, es suficientemente amplio como para poder establecer hipótesis de partida y tendencias al respecto. Por último, cabría reiterar que no pretendemos en absoluto realizar un estudio integral y exhaustivo de la vivienda urbana en el siglo II d.C., algo que excede con mucho el fin de este trabajo, sino analizar de forma amplia y, a la vez, obligatoriamente sintética, los principales rasgos de los espacios domésticos de las ciudades citadas en el marco temporal propuesto.

\section{ESTUDIO DE CASOS}

\subsection{Bética}

Colonia Patricia

La evolución de la arquitectura privada en Colonia Patricia durante la segunda centuria de nuestra era ha de trazarse con base en testimonios arqueológicos indirectos, debido, entre otros factores, a la falta de viviendas excavadas en extensión y a su carácter de ciudad superpuesta, esto es, habitada desde su fundación (Carrillo 1999: 77-80, Vaquerizo 2004: 81-94, Márquez 2005: 54-56). Estos vestigios revelan que las viviendas gozaban de un gran nivel decorativo y que sus comitentes estaban al tanto de las novedades estilísticas de moda en Roma, lo que sirve para definir al periodo antonino como una época de esplendor para la arquitectura residencial local. En esta línea, las estatuas-fuente, hermas-retrato, hermas báquicas y monopodia decoradas constituyen la decoración escultórica de carácter doméstico predominante durante el siglo II (Peña 2011: 54). Del elenco de pavimentos musivos documentados, destacan una mayoría que pueden ser estilísticamente datados en dicha centuria, lo que hay que poner en relación con reformas decorativas de domus preexistentes (Secilla y Márquez 1991: 341, Moreno 1996: 81 y 84). Del mismo modo, una parte importante de los capiteles reutilizados en la Mezquita Aljama fueron labrados en el siglo II y pudieron pertenecer a viviendas (Márquez 1993, Peña 2010). Aun así, existen evidencias de la ampliación de domus, cuya planta no se ha podido documentar completamente, y que ocuparon, en parte, el viario público, 
como es el caso de la documentada en plaza Pineda 2 (Ruiz Bueno 2014: 46-47, 2015: 102).

Este dinamismo también se detecta en las áreas suburbanas. Los suburbia occidental y oriental se colmaron de inmuebles y se expandieron más allá de sus límites tradicionales, al mismo tiempo que se operó en ellos un retroceso de la función funeraria frente a la habitativa y comercial (Ruiz Bueno 2018: 265-266). El mejor ejemplo de vivienda suburbana lo constituye la domus del Sátiro, que sobresale por la calidad de sus revestimientos pictóricos, fruto de una intervención decorativa de época antonina. Esta fase no llegó a ser concluida y la casa se abandonó por motivos que ignoramos a finales del siglo II (Cánovas 2010: 427-438).

\section{Astigi}

Las diversas intervenciones arqueológicas que se han sucedido en el solar de la Écija romana han sacado a la luz no pocos testimonios de viviendas. Sin embargo, hasta el momento ninguna ha podido ser analizada en toda su extensión. La cantidad de unidades domésticas que se reformaron o construyeron en la segunda centuria es amplísima y solo su descripción ocuparía largo espacio (un compendio actualizado sobre las estructuras que se adscriben a espacios domésticos en García-Dils 2015: 287-443). Normalmente, las domus excavadas presentan dos fases constructivas: la primera se fecha entre época fundacional y la primera mitad del siglo I d.C., mientras que la segunda ocupa todo el siglo II d.C., especialmente su segunda mitad (Sáez et al. 2004: 58, García-Dils et al. 2009: 524). Entre las últimas estructuras habitacionales excavadas hay que destacar las documentadas en la plaza de España: las llamadas casa de las Hermae y casa del $O s-$ cillum. Ambas fueron reformadas en el siglo II. En el caso de la domus del Oscillum, la segunda centuria trajo consigo un cambio de envergadura: el vestibulum que daba acceso a la vivienda desde el kardo maximus y que, por ende, constituía su entrada principal, se amortiza para construir una estructura sobre grandes basamentos interpretada como una porticus (García-Dils et al. 2009: 533, García-Dils et al. 2011: 268-269). En cuanto a la casa de las Hermae, su estructura fue modificada en las postrimerías del siglo II para acoger unas tabernae. Igualmente, se reformó el atrio-peristilo y se renovó su aparato decorativo con tres retratos de los que sólo conocemos sus pedestales (García-Dils et al. 2006: 353 y 363) (AE 2006, 647; $A E$ 2006, 648; $A E$ 2006, 649).
La casa excavada en el solar de plaza de Santo Domingo 5 y 7 , en el sector nororiental de la colonia, constituye un caso particularmente interesante. Se trata de una vivienda construida a finales del siglo I o en los primeros años de la centuria siguiente. Resulta realmente llamativo que esta fuese la primera edificación que albergó la parcela; es decir, la casa fue erigida sobre un solar baldío situado intramuros y que, además, estaba perfectamente delimitado por el viario. La excavación no detectó una fase edilicia previa, únicamente los rellenos de tierra propios de los trabajos de urbanización datados, gracias a la presencia de fragmentos de cerámica, en época fundacional (Romero Paredes et al. 2006: 58-59). Por lo tanto, estamos ante una insula intraurbana que no acoge ninguna construcción hasta un siglo después de la fundación de la colonia (Romero Vera 2014: 937-940).

El cúmulo de información sobre el área suburbana occidental es mayor, ya que allí se han desarrollado más procesos de sustitución inmobiliaria en los últimos años. Así, las intervenciones han revelado que, desde época augustea, el suburbium occidental poseyó funciones diversas. Se han documentado tumbas, vertederos e instalaciones vinculadas con la producción de aceite. A partir de época julio-claudia, comenzaron a erigirse algunas viviendas, pero desde finales del siglo I y durante todo el II se desarrolló una transformación de envergadura: el espacio cambia de uso y adquiere, casi en exclusiva, una función residencial. En efecto, la práctica totalidad de este sector fue ocupado por viviendas de notables dimensiones, propias de una clase pudiente (Rodríguez Termiño 1991: 346-352, Vera et al. 2005: 494, García-Dils et al. 2006: 359).

En el suburbio oriental, justo en la lengua de terreno situado entre las murallas y el cauce del río Singilis, parece que se dio una situación análoga. Allí se han desarrollado menos intervenciones, pero todo apunta a que, igualmente, esta área tuvo una función netamente residencial en la segunda centuria y que las viviendas situadas allí comenzaron a edificarse a partir de dicho siglo. Por tanto, este constituye el primer episodio de ocupación doméstica del suburbio oriental (Carrasco y Romero Paredes 2001: 576-579).

\section{Baelo Claudia}

Hasta la actualidad, tan solo se han identificado dos viviendas altoimperiales en Baelo Claudia, ya que, como es frecuente en este tipo de yacimiento, los esfuerzos se han centrado en estudiar el foro y los edificios 
públicos. Tanto la casa del Cuadrante como la casa del Oeste se encuentran situadas en el barrio industrial pesquero-conservero que ocupa el sector meridional de la ciudad (Arévalo y Bernal 2007). Ambas fueron excavadas por Pierre Paris y su equipo a principios del siglo pasado, hecho que dificulta tanto su interpretación como la datación de las fases que presentan (Sillières 1991: 321-324). Para el caso de la domus del Cuadrante se han analizado unos grafitos repartidos por varias estancias en el estrato preparatorio de sus pinturas murales. Su análisis paleográfico ha ofrecido un terminus ante quem para, al menos, datar las pinturas a mediados del siglo II (Bonneville et al. 1988: 94 y 96). Posiblemente, pertenezca a esta misma fase la reforma de la sala 51, interpretada como triclinio, puesto que se detecta en sus muros el empleo de incertum o pseudo vittatum de caliza y arenisca, cuyo uso se atestigua en la ciudad en época trajanea (Sillières 1991: 324-326, Diderjean et al. 1986: 128). Por su parte, la casa del Oeste fue ampliada en época antonina. Corresponden a este horizonte constructivo las habitaciones número 32 y 33 , estancias de aparato con las que se amplía la casa en detrimento de una cetaria vecina (Sillières 1991: 324-326, Sillières 1997: 173).

El uso residencial de ambas casas no supera el siglo II. Se plantea que fueron abandonadas a mediados de esta centuria, ya que se ha comprobado que algunas de sus estancias fueron ocupadas por piletas $\mathrm{y}$, por tanto, pasaron a tener una función productiva (Bernal et al. 2007a: 129-130 y 187). Por último, hay que citar el llamado Edificio Meridional III, construcción de difícil interpretación de la que no está clara ni su función residencial ni su identificación con una factoría de salazón. En cualquier caso, se ha comprobado que dicho edificio se amortiza a finales del siglo II (Bernal et al. 2007a: 194-200). Hecho que no determina su definitivo abandono, puesto que a partir de esa fecha adquiere un uso incierto, posiblemente marginal, y se convierte en un lugar de deposición de desechos que elevaron la cota de hábitat dos metros. En dichos estratos se han hallado materiales relacionados con actividades pesquero-conserveras que llegan hasta el siglo IV (Bernal et al. 2007a: 198-199, 2007b: 389-395).

\section{Italica}

La falta de registro estratigráfico con la que se efectuó la excavación de la mayor parte de las viviendas documentadas en Italica obliga a tomar en consideración otro tipo de información (Mañas 2010: 82). En este sentido, el estudio de los pavimentos musivos ha servido para trazar una evolución general de la arquitectura doméstica italicense. Así, de los ochenta y dos mosaicos y opera sectilia que ha aportado el yacimiento, la mayor parte pertenece a la segunda mitad del siglo II (Mañas 2011: 91). Esta datación, ciertamente tardía, nos ilustra sobre el proceso de urbanización de la Nova Urbs. En primer lugar, se desarrolló la planificación y construcción del trazado viario, cloacas y acueducto, para proceder después a la erección de los edificios públicos y espacios monumentales (Traianeum, Termas Mayores, anfiteatro, etc.). En última instancia, ya durante el reinado de Antonino Pío, se construyó y decoró el grueso de las viviendas (Mañas 2009: 197). Esta secuencia deja patente que existió un cierto desfase temporal entre la arquitectura de iniciativa imperial o pública y la edilicia privada.

En otro orden de cosas, la única vivienda cuyo abandono se constata dentro del siglo II corresponde a la casa de las Columnas, cuya amortización se fecha a finales de dicha centuria (aunque volvería a ser reocupada a finales del siglo III) (Abad 1982: 146-148). Con todo, las intervenciones decorativas en ámbito doméstico no se circunscriben a la etapa tardoantonina, ya que en época severa se han detectado ciertas actuaciones puntuales (Mañas 2009: 194-196). En efecto, cuatro pavimentos de la casa del Nacimiento de Venus y el opus sectile de la casa de la Exedra (fruto de la repavimentación de una estancia) pertenecen a esta fase (Canto 1976: 293-318, Roldán 1991: 303-311).

\section{Munigua}

El aspecto más destacable sobre la arquitectura doméstica en Munigua es el escaso número de viviendas que formaban parte del tejido urbano. En efecto, se piensa que la mayor parte de la población local se encontraba dispersa por el territorium adscrito a la ciudad y que solo unas pocas familias habitaron el núcleo urbano (Hauschild y Haussmann 1991: 329-335, Schattner 2003: 223). La principal fase de la edilicia doméstica local se desarrolla entre finales del siglo I y principios del II. La casa 1 adquirió su articulación arquitectónica definitiva en esta etapa. Dicha vivienda tiene forma trapezoidal y estaba formada por 22 estancias, entre las que destacan el triclinio y el peristilo que articula todo el edificio (Hauschild 1985: 235-267, Meyer et al. 2001: 50-65). Igualmente, la casa 2 fue reformada a finales del siglo I o principios del siglo II, después 
de que una parte de su solar se desgajara para la construcción de la basílica forense (fig. 2). Para paliar esta pérdida de espacio, la residencia fue ampliada hacia el sur, construyéndose dos estancias dedicadas al comercio (habitaciones 3 y 4) y otra empleada como almacén de ánforas (Meyer et al. 2001: 260-261). Por último, también la casa 6 , con una distribución muy parecida a la casa 1, se edificó dentro de la misma fase constructiva (Vegas 1985: 269-289, Meyer et al. 2001: 65-76).

\subsection{Lusitania}

\section{Augusta Emerita}

Además de por sus espacios públicos, la Mérida romana destaca por la gran cantidad de estructuras habitacionales y elementos decorativos domésticos que se han hallado en su subsuelo. De hecho, es la capital provincial hispana que más volumen de información referente a la vivienda ha aportado, de forma que resulta complicado citar cada uno de elementos relativos a la arquitectura doméstica emeritense adscritos a la época de nuestro estudio (Corrales 2016).

Parece que en esta colonia preponderaron las casas con un único espacio de distribución abierto, fundamentalmente un peristilo (Alba 2004: 67 y ss., Corrales 2016: 139-143). Asimismo, buena parte de las viviendas documentadas presenta un horizonte constructivo en el siglo II d.C. (Palma 1997: 367-386). Sin embargo, se ignora en gran medida el estado que presentaban en dicho periodo, ya que sufrieron profundos cambios en el siglo IV que enmascararon el aspecto de las viviendas altoimperiales (Palma 1997: 362). Con todo, dentro del lenguaje decorativo del siglo II hay que destacar el predominio de los mosaicos bícromos en la primera mitad de siglo, momento a partir del cual se imponen los polícromos. En cuanto a la producción pictórica, los dos primeros siglos del Imperio están marcados por la abundancia de composiciones clásicas de clara raigambre itálica, dotadas de rodapié y zócalo, en las que predominan las texturas pulidas (Corrales 2016: 262-263). No obstante, la incorporación de balnea supone el rasgo más sobresaliente de la edilicia doméstica emeritense de época antonina. En relación con ello, cabría destacar dos ejemplos: por un lado, la suntuosa vivienda documentada en la c/ Félix Valverde Lillo 7, cuyas dependencias destinadas al baño ocuparon una extensión de $90 \mathrm{~m}^{2} \mathrm{y}$, por otra parte, la casa 5 del área arqueológica de Morería, la cual contó con todos los espacios propios de unas termas públicas, es decir, apodyterium/frigidarium, tepidarum y caldarium. Dicho balneum se ubicó en un costado de la vivienda y se accedía a él a través del peristilo (Corrales 2016: 264).

Por lo que respecta a las áreas suburbanas, las excavaciones arqueológicas han atestiguado la existencia de un gran foso que defendía el flanco este de la colonia. Se trataba de un corte realizado en el estrato geológico que corría en paralelo a la muralla, a unos $25 \mathrm{~m}$ de ésta. Así, el espacio suburbano oriental más inmediato a la ciudad estuvo caracterizado desde época fundacional por la presencia de este elemento defensivo (Pérez Maestro 2005: 238). Entre finales del siglo I y principios del II, esta zanja fue amortizada con vertidos de desechos domésticos y constructivos. Una vez colmatada, esta área suburbana se aprovechó para la edificación de construcciones domésticas. Sobre los propios estratos de colmatación del foso se han documentado las cimentaciones de las domus que se erigieron allí desde inicios del siglo II. Esta dinámica parece estar relacionada con la demanda de nuevos espacios extramuros para la instalación de viviendas (Pérez Maestro 2005: 239).

Dentro de esta misma línea, se tiene noticia de varias estructuras domésticas suburbanas emeritenses (entre las que cabría citar las que se han documentado en el llamado "solar de Resti") datadas por su decoración pictórica en el transcurso del siglo I al II (Márquez 2010: 146). De esta misma cronología es la conocida como casa del Albarregas, situada junto al río, al noroeste de la ciudad, cuyos restos se corresponden con tres habitaciones y un conjunto termal privado (Márquez 2010: 147). Por su parte, la casa del Mitreo, aunque erigida a finales de siglo I, también presenta una interesante fase fechada a inicios del siglo II, cronología que cabría dar tanto a los pavimentos como las pinturas de las diversas estancias. A una fase posterior, entre la segunda mitad de siglo II e inicios del III, pertenece el conocido mosaico cosmogónico (Álvarez y Nogales 2011: 484).

\section{Conimbriga}

El estudio de la arquitectura doméstica de esta ciudad no es una cuestión sencilla. A pesar de que Conimbriga ha ofrecido numerosos ejemplos de viviendas, la mayor parte de estas fueron excavadas en una época en la que no existía una metodología muy depurada, lo que implica, en última instancia, que haya problemas para datar con fiabilidad sus diferentes fases constructivas. 


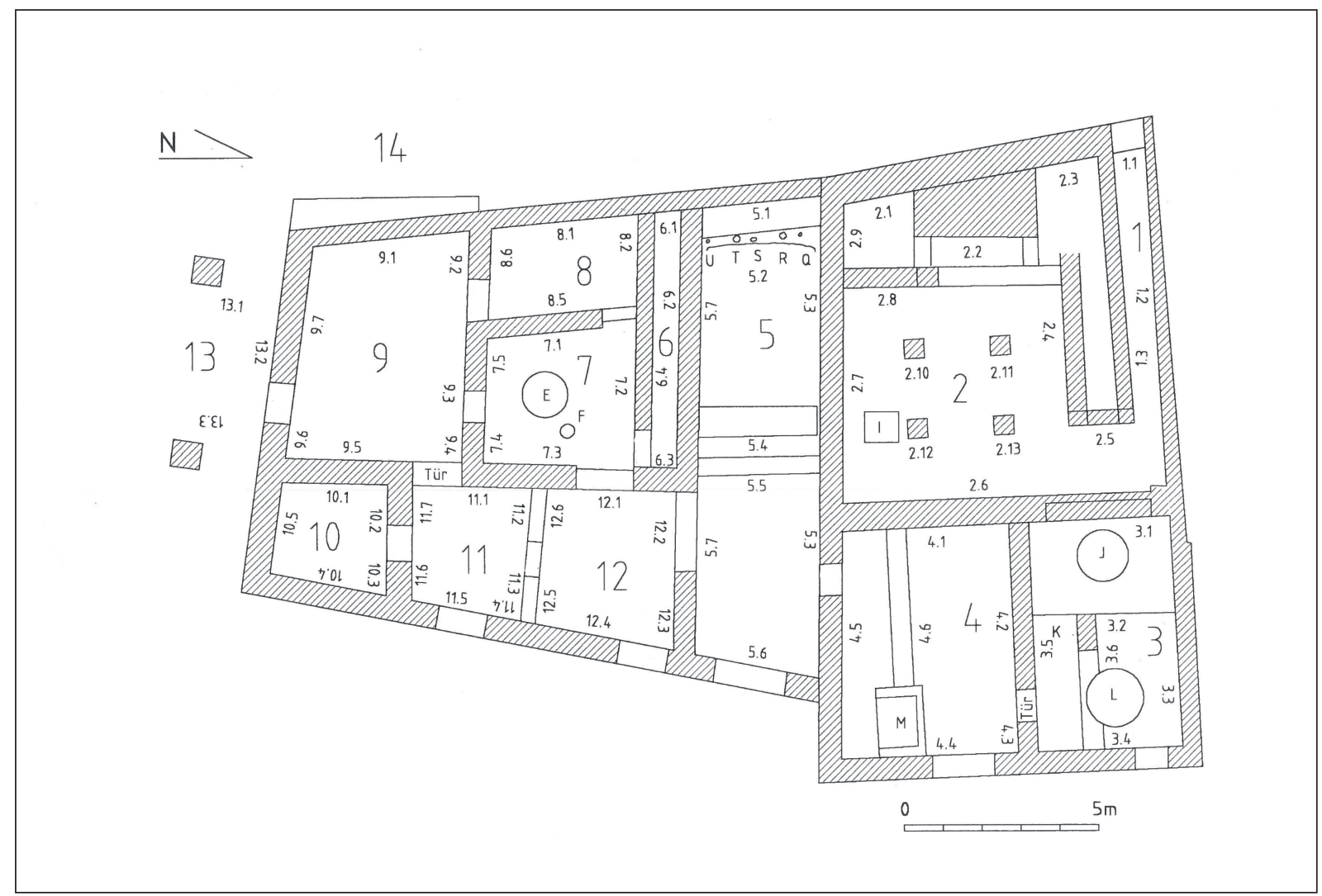

Figura 2. Planta de la segunda fase de la casa 2 (a partir de Meyer et al. 2001: 222, fig. 7).

A pesar de todo, en general, se observa que en la época de nuestro estudio casi todas las intervenciones arquitectónicas son de pequeña escala o de orden decorativo (Correia 2010b: 8-9). Un fenómeno propio del siglo II es el equipamiento de baños privados en las casas, detalle indicativo de la riqueza de los propietarios (Correia y Reis 2000: 279).

Una de las domus más sobresalientes del municipio es la casa dos Repuxos (Morand 2005, Correia 2013: 149-156). La segunda fase de la misma supuso la construcción del gran impluvium ajardinado (y decorado con un sistema de 521 surtidores) del que deriva su moderna denominación (fig. 3) (Correia 2004: 5455, Reis y Correia 2006: 296-298). El acceso original al edificio fue amortizado y se edificó en su lugar una entrada monumental (Correia 2013: 155). También corresponde a esta fase la construcción de unas pequeñas letrinas (Reis et al. 2011: 195-196). Por su parte, a finales del siglo II, la casa atribuida a Cantaber se dotó de unos baños privados en los que no falta ninguno de los espacios propios de las termas públicas (fig. 4) (Correia y Reis 2000: 276-277, Correia 2001: 83-140). También la casa de los Esqueletos, en su aspecto final, se data en la segunda centuria. Esta suntuosa domus se articula en torno a un peristilo central porticado y con estanque (Reis y Correia 2006: 304-305, Alarcão 2010: 46-63, Correia 2013: 169-174).

\section{Mirobriga Celticorum}

A pesar de que se han excavado varias estructuras domésticas, tan solo dos casas revisten interés para nuestro estudio (Barata 1999: 51-68, 1998: 59-62). Junto a la actual capilla de San Blas se excavó una gran domus (de cerca de $300 \mathrm{~m}^{2}$ ) organizada en torno a un atrio. Con toda seguridad, la casa formaba parte del paisaje doméstico de Mirobriga en la segunda centuria, puesto que presenta una larga e ininterrumpida ocupación que va del siglo I al V d.C. (Barata 1999: 55-59). Igualmente, se ha podido determinar que la casa 1 , situada junto a las termas, fue ampliada en época flavia y estuvo en uso hasta finales del siglo III (Teichner et al. 2014: 1121-1124). 


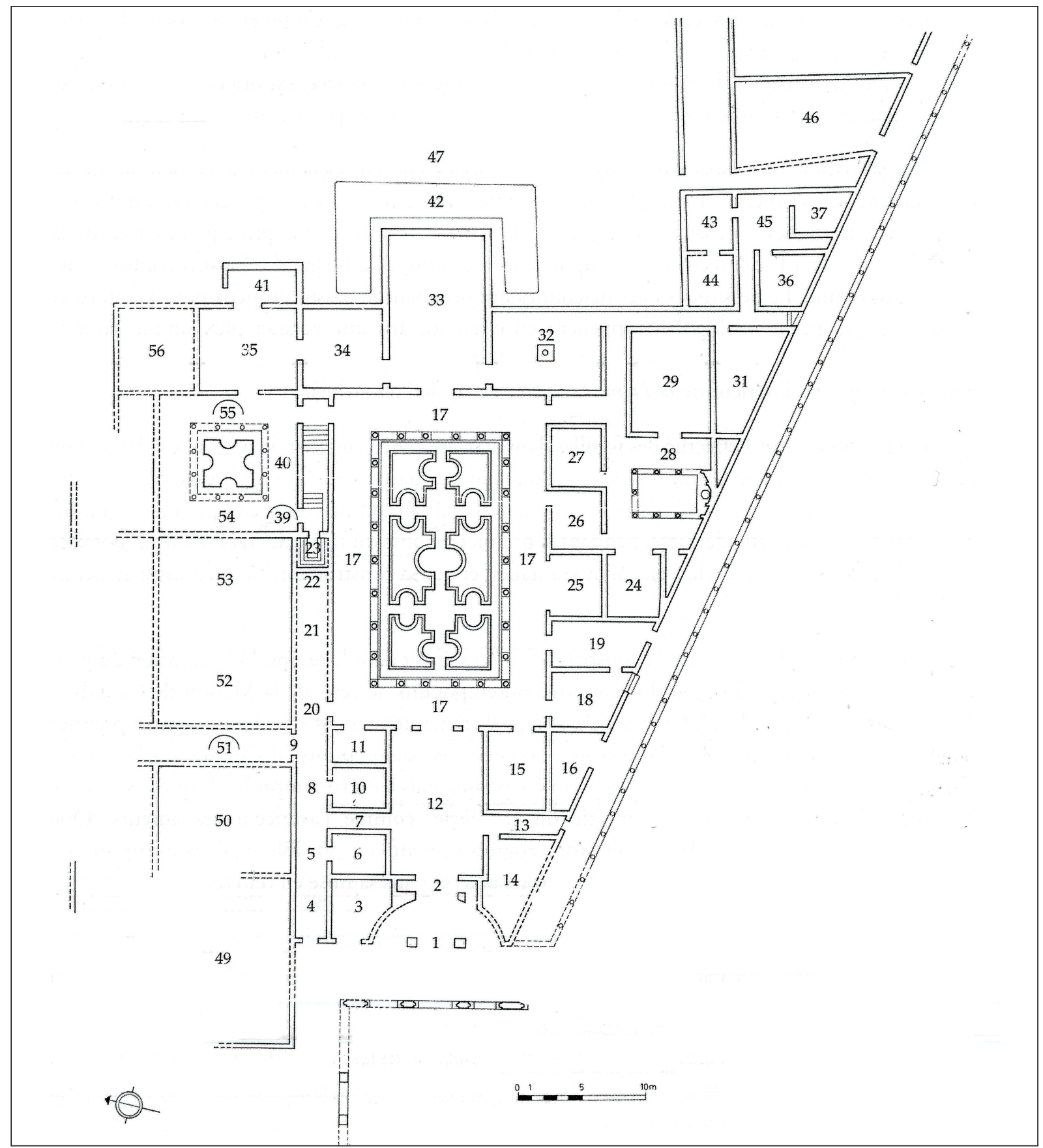

Figura 3. Planta de la segunda fase de la casa dos Repuxos (a partir de Morand 2005: 21, fig. 4).

\subsection{Hispania Citerior}

\section{Tarraco}

Existe un cierto desfase entre el nivel de conocimiento de los conjuntos públicos de Tarraco y el de su arquitectura doméstica. La información arqueológica sobre la vivienda, principalmente la de la zona intramuros, es escasa y fragmentaria debido a las dificultades con las que ha contado su estudio. En especial, la apertura de ensanches en el siglo XIX y XX, que eliminaron gran parte del registro arqueológico 


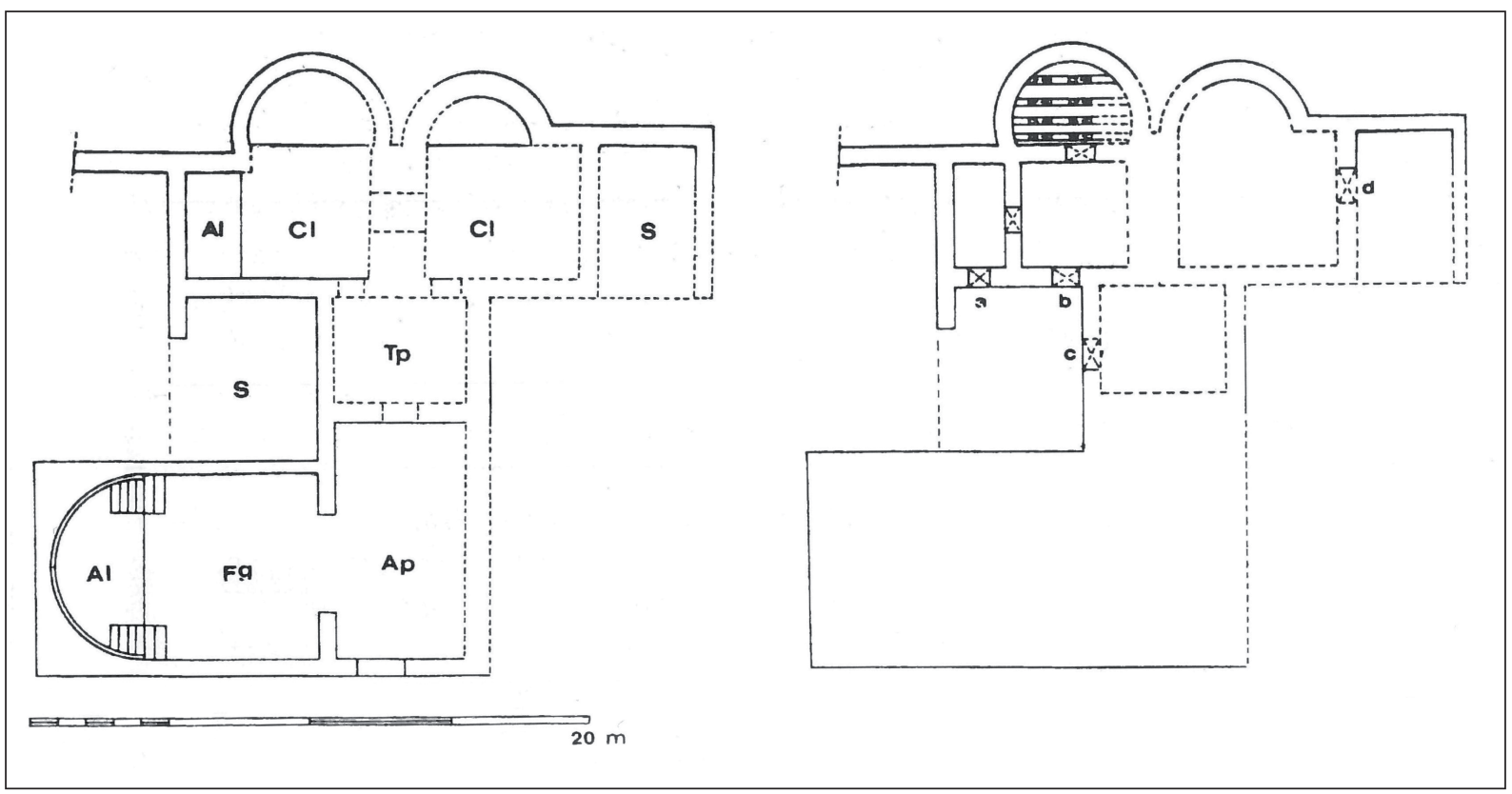

Figura 4. Planta del balneum de la casa de Cantaber (a partir de Correia y Reis 2000: 276, fig. 4).

de una zona ocupada, esencialmente, por residencias (Perich 2014: 119-122). Con todo, el registro arqueológico revela que el siglo II fue una etapa de esplendor en lo que respecta a la edilicia doméstica (Cortés 2009: 517). De hecho, existe un buen número de esculturas de carácter ideal adscritas a casas y jardines que fueron elaboradas en época antonina (Koppel 1985: 69 ss. y 100 ss.).

Por lo que respecta a ejemplos domésticos intraurbanos, debemos citar la domus descubierta en c/ Gobernador González 17, cuyo aparato ornamental, mosaicos y revestimientos pictóricos fueron renovados en época antonina (Mar et al. 2012: 143). La periferia urbana más cercana a la muralla, sobre todo en el costado suroeste, adquirió desde época augustea una apariencia prácticamente urbana, debido al elevado número de viviendas que ocuparon ese espacio (Macias 2004: 76). Dentro del siglo II, se reconstruyen y reforman algunas de estas viviendas. Es el caso de una domus de cronología augustea hallada en la excavación de la c/ Alguer 9, situada a pocos metros de la muralla occidental. En época antonina fue reformada, constituyéndose en una casa articulada en torno a un peristilo porticado de planta irregular, ornamentado con una fuente central. La casa destaca por su profusa decoración: pavimentos que combinan el sectile y el signinum (este último para las zonas cubiertas de lechos), zócalos decorados con pinturas, así como un triclinio enlosado con un opus sectile de mármoles locales y de importación que forman motivos geométricos (Macias y Puche 1997: 153-154, Perich 2014: 133). Otro ejemplo se encuentra en el suburbio portuario. Se trata de la domus de c/ Eivissa 9, conocida solo parcialmente, que presenta un triclinio decorado con pinturas y un larario, así como una galería cubierta de pinturas que representan una venatio (fig. 5) (Adserías et al. 2000: 140, Macias et al. 2007: 144-145). Finalmente, la vivienda documentada en avda. Prat de la Riba 9 incorporó en este siglo un triclinium aestivum (Cortes 2009: 517). Al margen, en época antonina también se reconoce este mismo proceso de embellecimiento y reformas en viviendas situadas en el extrarradio urbano y en las villae diseminadas por el ager Tarraconensis (Macias 2001: 40-50, Keay 2004: 102).

\section{Caesar Augusta}

Aunque parcial, la información disponible sobre las viviendas de Caesar Augusta es abundante y, pese a sus limitaciones, posibilita un conocimiento general del estado de la arquitectura doméstica en el siglo II (Beltrán y Mostalac 2007: 78-81). Por un lado, es necesario señalar que entre los materiales de construcción empleados en este periodo no figura, curiosamente, el ladrillo. Eso sí, muchas domus fueron pavimentadas con mosaicos como es el caso de las estructuras domésticas 


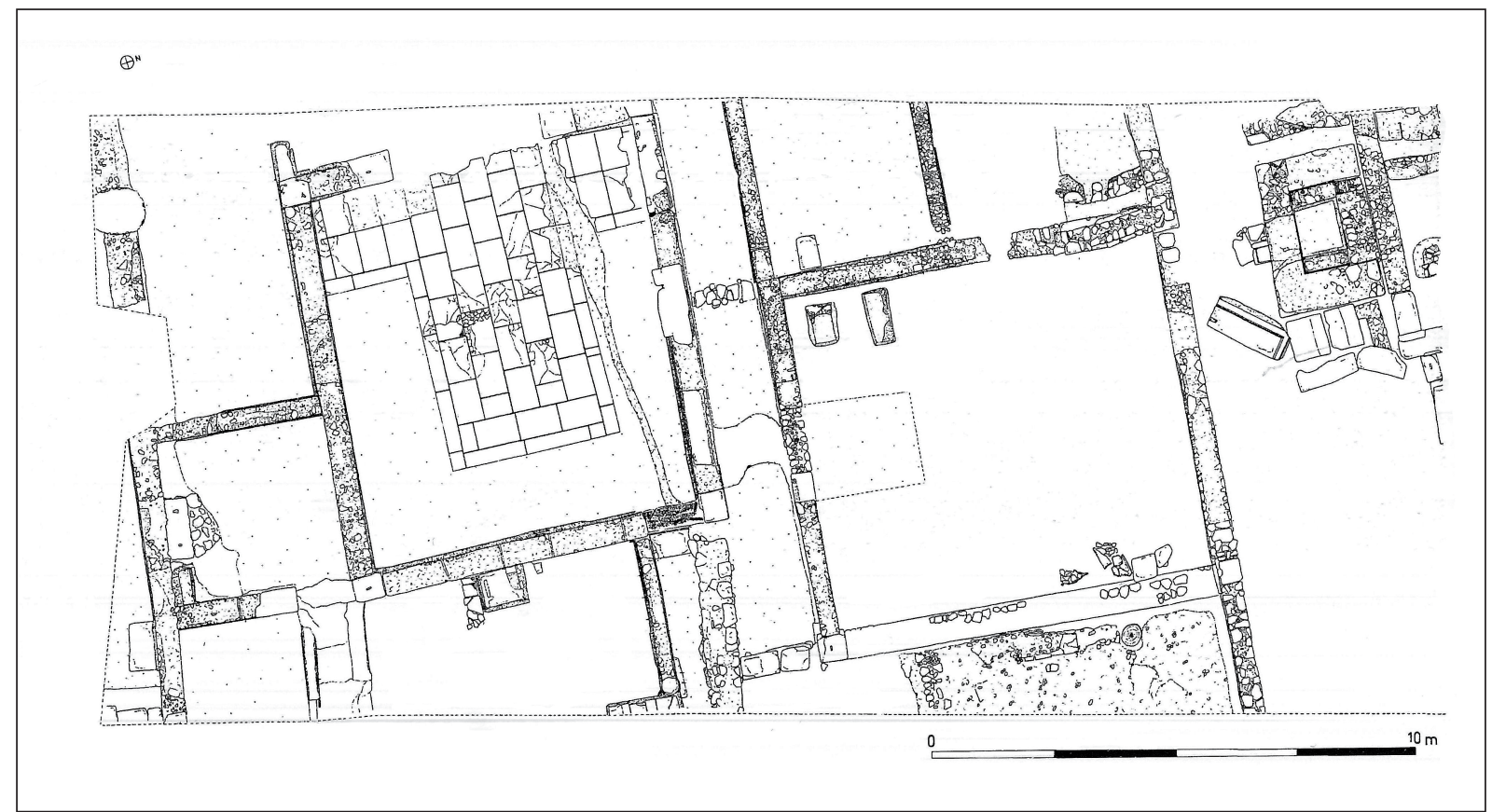

Figura 5. Planta de los restos exhumados de la domus de c/ Eivissa 9 (a partir de Adserías et al. 2000: 148, fig. 12).

exhumadas en c/ Torrenueva 6 y c/ don Jaime (Beltrán et al. 1985, Paz 1991: 21). Por otro lado, algunas excavaciones han sacado a la luz evidencias de balnea como los hallados en la plaza de Santa Marta. En el ángulo noroeste de la ciudad se encuentra la llamada casa de Orfeo, una domus de grandes dimensiones que ha ofrecido notables mosaicos fechados entre finales del s. II y principios del III (Beltrán y Mostalac 2007: 80-81). Para cerrar este apartado, recordemos en último lugar el soberbio ejemplar de escultura de ambiente doméstico cuyo emplazamiento original fue, probablemente, un peristilo. Se trata del llamado "grupo Ena", una escena de ninfas en acto musical datada en época trajanoadrianea (fue hallado en el número 15 de la c/ del Coso) (Koppel y Rodà 2007: 119-120).

En la periferia urbana también han salido a la luz estructuras domésticas. Es el caso de la villa suburbana de la calle Alonso V-Rebolería, de la que solo se ha podido documentar un ambiente porticado en el que apareció una estatua-fuente que representa a un fauno ebrio recostado sobre un lecho (fig. 6) (Beltrán 1952: 439-445). Esta magnífica escultura, elaborada en mármol de Tasos, estuvo destinada a ornar el peristilo de la villa. Se ha datado entre los reinados de Adriano y Antonino Pío (Koppel y Rodá 2007: 120). Una cabeza de sátiro constituye otra singular pieza de ambiente doméstico. Fue hallada en la inmediata periferia, en la calle Teniente
Coronel Valenzuela 6. En este caso, la escultura se data en la segunda mitad del siglo II (Koppel y Rodá 2007: 121-122). La excavación del solar situado en la calle Palomar 4 ha deparado el hallazgo de dos conjuntos pictóricos y cinco fragmentos de cornisas de estuco fechados en el siglo II, que pertenecieron a la reforma decorativa de una vivienda (Guiral 2015: 125-130). Un gran número de viviendas suburbanas, incluida las dos citadas anteriormente, se abandonan en el transcurso de la segunda centuria. Es el caso de las domus de calles Predicadores 24-26, plaza de España, Palomeque 12 y plaza de San Miguel. Esta dinámica de abandonos se ha querido relacionar con una posible restauración o reforma de la cercana línea de muralla, teoría para la que, de momento, no existe refrendo arqueológico (Beltrán y Fatás 1998: 62-64, Beltrán y Mostalac 2007: 78).

\section{Carthago Nova}

En lo que concierne a la arquitectura doméstica de Carthago Nova, durante toda la primera mitad del siglo II d.C. se aprecia cierta ebullición centrada, especialmente, en la actualización de los programas decorativos de antiguos inmuebles (Fernández Díaz y Quevedo 2008: 283). Así lo atestigua la aparición de toda una serie de elementos: piezas arquitectónicas de 
carácter ornamental, pavimentos marmóreos de importación, pinturas murales del IV estilo y un buen conjunto de esculturas domésticas y de jardín (Noguera 2002a: 85-86, Soler 2005: 52, Soler 2017: 85, Fernández Díaz 2017: 79-82). Entre las domus que presentan un horizonte constructivo datado en la primera mitad de la segunda centuria se encuentra la situada en la c/ Gisbert 14, donde se han hallado unos capiteles corintizantes de mármol blanco de esta época. O bien, la llamada domus de la c/ Saura, situada en la ladera septentrional del Monte Sacro, cuyo triclinium fue ornamentado con un opus sectile datado también en este periodo (fig. 7) (Soler 2003: 161, Fernández Díaz y Quevedo 2008: 286-287). Dicho inmueble sufrió varias remodelaciones hasta su amortización definitiva. Entre las pinturas más interesantes del conjunto se encuentran las de la habitación V (datada a mediados del siglo II) y las de la estancia VI (de inicios de la segunda centuria) (Martín et al. 2001: 41 y ss.). Igualmente, la domus de la Gorgona presenta un pavimento de opus tessellatum de similar cronología (Fernández Díaz y Suárez 2006: 96-100).

Este panorama contrasta abruptamente con el que se registra en la segunda mitad del siglo II. De todos los cambios que experimentó la ciudad en este marco temporal, el más llamativo es, sin duda, el abandono del sector centro-oriental, área con una marcada función residencial. De este modo, a finales de siglo se produce un abandono en cadena de muchas domus, construidas a inicios de la época imperial, algunas de las cuales habían sido rehabilitadas a principios del siglo II. Las intervenciones arqueológicas llevadas a cabo en los últimos años demuestran que el espacio habitado se redujo al extremo más cercano al puerto y que la población se replegó en la lengua de terreno existente entre el cerro del Molinete y el de la Concepción (Vizcaíno 1999: 93-95).

Por tanto, la retracción de Carthago Nova se hace patente en la reducción de la extensión habitada a prácticamente la mitad del espacio delimitado por sus antiguas murallas (Noguera 2002b: 85, Ramallo 2006: 453). Pero no solo se registran abandonos en aquel sector, también fueron deshabitadas algunas casas de la parte occidental (Ramallo y Vizcaíno 2007: 495). Los inmuebles situados en c/ Duque 33, Beatas, Caballero 7 y 8, plaza de la Merced 1, Cuatro Santos 40, Serreta 3 y 9, así como las domus de Fortuna, de la Gorgona, del Peristilo Pintado, del Sectile y del Barrio universitario, presentan una fase de abandono homogénea, situada cronológicamente en la segunda mitad de siglo II d.C. (Vizcaíno 1999: 93, Ruiz 1996: 503-514,

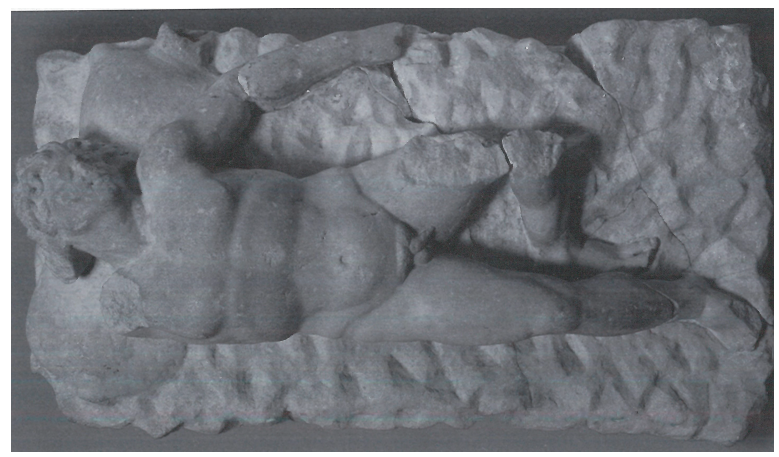

Figura 6. Fauno (a partir de Koppel y Rodá 2007: 121, fig. 11).

Martín et al. 2001: 47-48, Soler 2003: 168, Madrid 2004: 69, Fernández Díaz et al. 2005: 143-144, Fernández y Quevedo 2008: 291, Fernández Díaz 2017: 79-82, Madrid 2017: 74-75).

No obstante, tal vez sería incorrecto indicar que estas viviendas fueron completamente abandonadas. Más bien se transformaron, pues de forma previa a su definitiva ruina acogieron nuevos usos artesanales y habitacionales. Las antiguas residencias fueron convertidas en improvisados talleres, mientras que algunas casas fueron compartimentadas. Por consiguiente, bajo el denominador común de la reutilización y la precariedad que trajeron consigo los nuevos tiempos, más que de "abandono" cabría hablar de cambio en el uso de las nobles domus altoimperiales (Soler 2003: 176, Fernández Díaz y Quevedo 2008: 300-301). A la vez, este sector se convierte en un lugar de expolio de materiales constructivos y de vertidos de residuos (Martín et al. 2001: 47, Fernández Díaz et al. 2005: 143, Egea et al. 2011: 292). Incluso en el hinterland de la ciudad se detectan niveles de abandono que revelan la severa regresión urbana que vivió Carthago Nova en esta etapa (Murcia 1999: 231-236).

Clunia

Casi todas las intervenciones acometidas hasta la fecha se han centrado en los espacios públicos de la ciudad, quedando aún por excavar la mayor parte del núcleo urbano, justamente aquellos sectores que fueron ocupados, previsiblemente, por viviendas. Aun así, existen algunos ejemplos de arquitectura doméstica en Clunia. Para el espacio cronológico que nos ocupa, hay que citar una intervención en la casa 1 (o de Taracena). Se trata, en concreto, de la ornamentación de dicha domus 


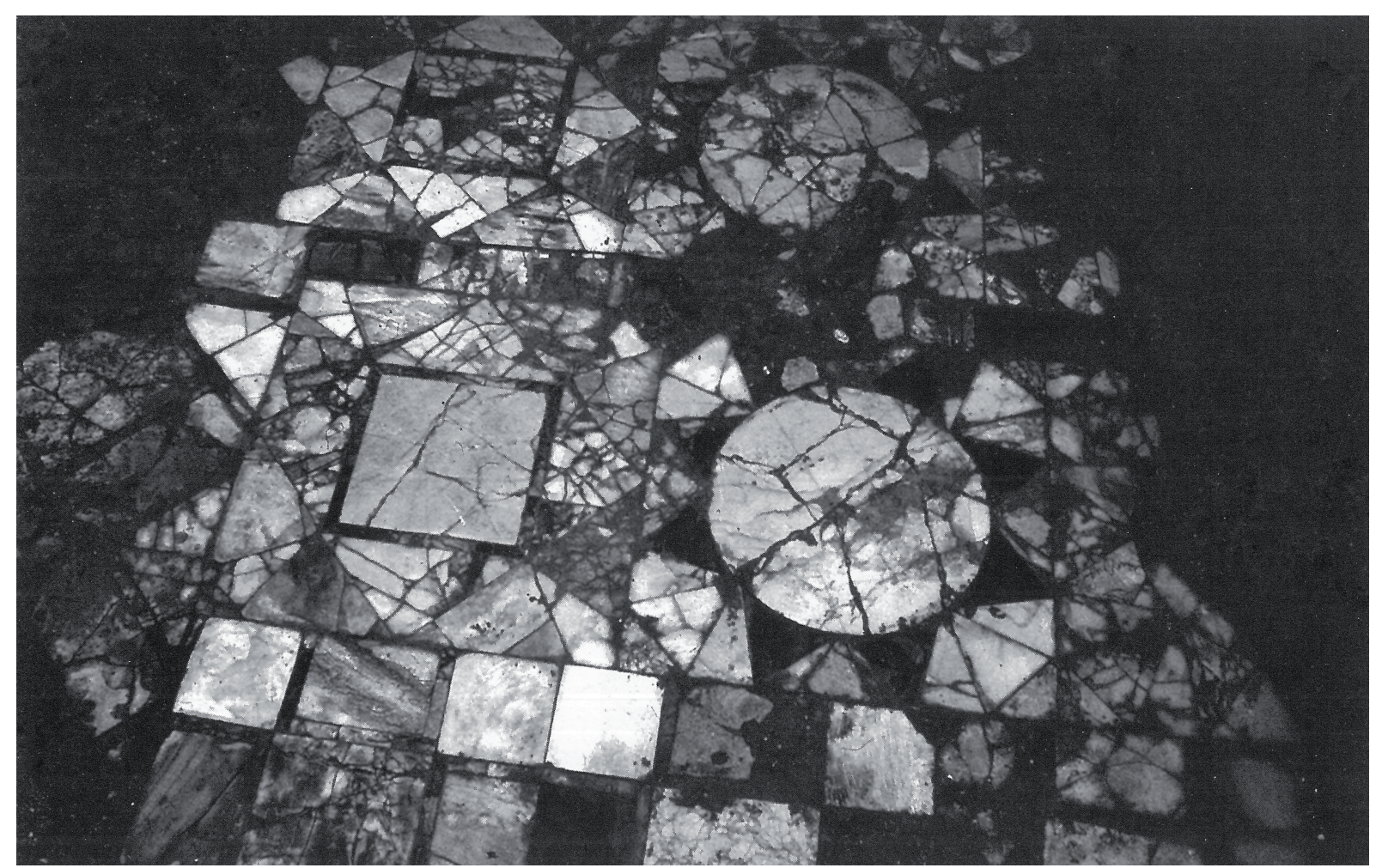

Figura 7. Opus sectile de la domus de la c/ Saura (a partir de Fernández Díaz y Quevedo, 2007-2008: 289, fig. 7).

con pinturas consistentes en plafones con temas florales geométricos propios de un momento avanzado de la segunda centuria (De Palol 1994: 46-48). Por otro lado, la habitación 8 de la casa 3 (o de la Ermita) presenta un mosaico geométrico y vegetal, con círculos en los que se representan cráteras, que ha sido fechado en un momento impreciso del siglo que nos ocupa ( $\mathrm{De} \mathrm{Pa}-$ lol 1994: 61-64). A este repertorio cabría sumar algunos elementos de decoración arquitectónica, basas y capiteles, procedentes de construcciones domésticas que apuntan una cronología de la segunda mitad del siglo II (Gutiérrez Behemerid 2002: 225-227).

\section{Asturica Augusta}

Posiblemente, la vivienda sea el aspecto mejor conocido de la Asturica del siglo II. Efectivamente, se han documentado, al menos, una decena de viviendas, de las cuales la mayoría presenta una fase constructiva o decorativa coincidente con nuestra etapa de estudio. A pesar de esto, debido a la naturaleza de las intervenciones arqueológicas en contexto urbano, ninguna de las domus ha podido ser excavada al completo.
A finales del siglo II o principios del III, la conocida como casa del Pavimento de Opus Signinum, situada en los aledaños del foro, incrementó su ya notable equipamiento con la construcción de un área termal de la que se han conservado una estancia calefactada y el praefurnium (fig. 8) (Burón 1997: 61-63, 2002: 265-266). Esta fase se completa con la pavimentación de dos corredores cercanos al peristilo con mosaicos polícromos de tema geométrico (Burón 1997: 63-64). La domus del Mosaico del Oso y los Pájaros se encuentra, también, muy cerca del foro. Se trata de una vivienda noble, fruto de varias fases, que incluye unas termas privadas (García y Vidal 1993: 23-28). A inicios de época severiana, el oecus o triclinium fue decorado con un mosaico de unos $70 \mathrm{~m}^{2}$ con figuraciones animalísticas y vegetales que da nombre a la casa (Regueras 1991: 140-154). Por su parte, la llamada domus de las Pinturas Pompeyanas destaca por la calidad de sus revestimientos pictóricos, fechados en el segundo cuarto del siglo II, calificados como uno de los mejores ejemplos de decoración pictórica de Hispania (Abad 1982: 293-295). Asimismo, la casa de las Columnas Pintadas ha ofrecido varios fragmentos de decoración pictórica compuestos por columnas estriadas que separan paneles datables a finales del 


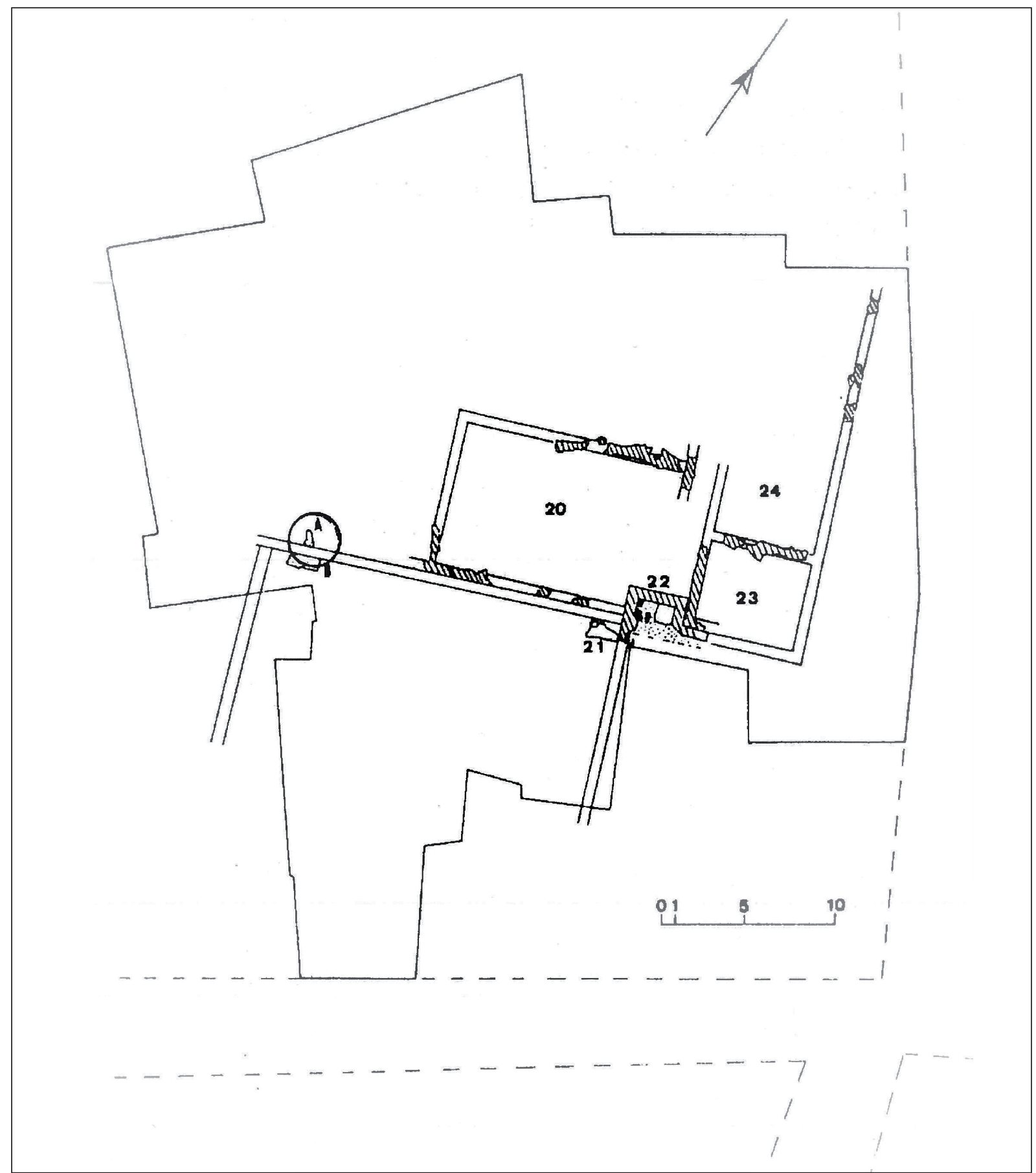

Fig. 8. Planta del balneum construido a finales del siglo II o principios del III, casa del Pavimento de Opus Signinum (a partir de Burón 1997: 63).

siglo I o principios del siglo II (García Marcos y Vidal 1999: 929-930).

La casa de la Muralla se emplazaba en el límite oriental de la ciudad. Fue derribada entre finales del siglo I d.C. e inicios de época antonina. Ya en pleno siglo II fue reedificada respetando su distribución anterior. De esta fase datan un área termal, varias estancias decoradas con pinturas murales del tercer estilo y 
zonas de servicio (García Marcos y Vidal 1999: 928929). El fenómeno del arrasamiento de las estructuras precedentes vuelve a darse en el caso de la domus del Gran Peristilo, situada en las inmediaciones de las Termas Mayores. En efecto, tras su derribo, en el siglo II, se construyó un peristilo porticado dotado de una gran fuente, alrededor del cual se establecieron las distintas habitaciones (García Marcos y Vidal 1999: 928).

\section{Bracara Augusta}

Las excavaciones desarrolladas en el antiguo solar de Bracara han sacado a la luz bastantes testimonios de estructuras domésticas. Sin embargo, la única vivienda excavada de forma íntegra es la llamada domus das Carvalheiras, una casa de atrio y peristilo construida en época flavia que ha sido tomada como paradigma de la casa bracaragustana (Martins 2009: 198). Con todo, V.H. Correia (2017: 33) interpreta la construcción como macellum. La vivienda, situada en el cuadrante noroeste de la ciudad, ocupaba en origen una extensión de $1.150 \mathrm{~m}^{2}$. En la primera mitad del siglo II, el sector al este del peristilo fue amortizado para la construcción de las termas homónimas. Hasta ese momento, dicho sector estaba ocupado por cubicula, así como por unas tabernae que abrían a una calle porticada (Martins 1997-1998: 32, Ribeiro y Martins 2013: 77). Otra estancia reestructurada en esta fase fue la sala situada al sur del peristilo, en cuyo espacio se crearon dos estancias interpretadas como cubicula (Magalhães 2010: 43). Finalmente, en la rua Santo António das Travessas se documentó una domus con restos de decoración pictórica cuya cronología se remonta a la segunda mitad del siglo I d.C. Esta vivienda fue destruida entre mediados y finales del siglo II para construir en su solar un edificio público de naturaleza desconocida (Magalhães 2010: 58-67).

\section{Emporiae}

El hecho de que solo se haya excavado una mínima parte de este municipio, sobre todo espacios públicos, limita bastante el nivel de conocimiento que tenemos sobre la arquitectura doméstica en Emporiae. No obstante, se han documentado varias domus de enorme extensión (casa 1 y casa 2B) no exentas de transformaciones en el periodo que nos ocupa. En este sentido, las viviendas acogieron una última reforma a inicios de siglo, antes de su abandono, momento en que la crisis ya era patente en la ciudad (Santos 1991: 34, Santos 2012: 69-70). En concreto, ambas casas incorporan estancias de uso convivial, conectadas con jardines interiores para ser usadas en verano. En la casa 1 la sala se construye a uno de los lados del peristilo. Además de pavimentarse determinados ambientes con mosaicos, entre los intercolumnios de dicho jardín se añadieron plutei decorados con imitaciones de crustae de mármol. En la casa $2 \mathrm{~B}$ se erigió un gran salón con antecámara abierto al hortus oriental (Santos 2012: 81-82).

Todo indica que estas grandes mansiones (cuya extensión total superó los $3.000 \mathrm{~m}^{2}$ tras su última reforma) serían muy difíciles de mantener y fueron presa de la dinámica de ruina que vive Emporiae en época antonina. Los materiales arqueológicos fechan el abandono final de las viviendas en la segunda mitad del siglo II (Mar y Ruiz de Arbulo 1993: 418, Santos 2012: 83).

\section{Baetulo}

Uno de los mejores ejemplos domésticos baetulonenses es la casa de Quinto Licinio, datada a finales del siglo I o principios del II. Se trata de un gran edificio que ocupa una extensión de $3.000 \mathrm{~m}^{2}$, enclavado junto a la puerta oriental de la ciudad. De hecho, curiosamente, la domus se asienta sobre la muralla fundacional, amortizando parte de su trazado. De entre sus múltiples espacios, destaca un gran peristilo decorado en su centro con un estanque absidiado de $13 \mathrm{~m}$ de longitud ( $\mathrm{Cu}-$ yás 1977: 139-142, Padrós y Sánchez 2014: 103). El nombre de la casa deriva del hallazgo en su interior de la tabula hospitalis de Q. Licinius Silvanus Granianus (AE 1936, 66). La datación de la vivienda, así como el hallazgo in situ de la tabula invitan a pensar que esta fastuosa vivienda pudo pertenecer al patrono de Baetulo (Guitart 1976: 139-142).

Además, hemos podido analizar algunas intervenciones de carácter menor en contextos domésticos. Es el caso de la casa 2, situada en el kardo minor II. A esta construcción pertenece una taberna que fue ampliada a inicios de la segunda centuria a costa de reducir las fauces de la propia vivienda (Padrós y Sánchez 2014: 111). En el patio de la casa documentada en la c/ Fluviá 23 se documentó una reforma datable en el primer cuarto del siglo II. Al parecer, el cerramiento de la boca de un pozo, así como la creación de un nivel de suelo que amortiza la huella de los dolia documentados en la fase previa, demostrarían que dicho espacio dejó de usarse como almacén (Guitart et al. 1991: 42). Por último, probablemente a inicios del siglo II, una de las 
de la casa del patio de la Rectoría de Santa María, edificada a finales del siglo I a.C., fue adornada con un mosaico polícromo con decoración geométrica (Guitart et al. 1991: 42).

A finales del siglo II y en época severiana el panorama cambió radicalmente. Se evidencia un proceso de abandono que repercute especialmente en la parte baja de la ciudad y en los aledaños del foro (Padrós y Sánchez 2014: 112). Efectivamente, las domus del Dofins y de l'Heura, ambas construidas en época augustea y situadas junto al foro, fueron amortizadas a finales del siglo II. También se han detectado niveles de abandono en el patio de la Casa 1 (Padrós y Sánchez 2014: 111). Este proceso afecta igualmente a un gran número de $t a$ bernae. Concretamente, en un solar adyacente a la Torre Vella se excavó una insula ocupada por cinco de estos espacios comerciales que se amortizó a mediados de la segunda centuria (Guitart et al. 1991: 45). Asimismo, en la calle Templo se efectuó un sondeo que sacó a la luz dos tabernae con planta superior cuyo derrumbe aconteció a mitad del siglo II. Por su parte, las tabernae pertenecientes a las casas 3 y 6 presentan unos niveles de abandono que se datan a finales del siglo que nos ocupa (Padrós y Sánchez 2014: 111-112).

\section{Barcino}

Las domus de la colonia suelen presentar dos características comunes: por un lado, se trata de casas nobles con estancias articuladas en torno a un atrio o peristilo; y, por otra parte, la mayoría data de finales del siglo I y principios del II (Beltrán de Heredia 2010: 35, Cortés 2011: 61). La domus de Sant Miquel, que, sin embargo, se remonta a época fundacional, sufrió una reforma entre finales del siglo I y principios del II, consistente en la instalación de un balneum que ocupó parcialmente una vía pública (Cortés 2011: 21 y 25, Miró 2011: 71-72). En la domus de la plaza de Sant Iu se ha documentado una habitación pavimentada con mosaicos y abierta a un viridiarium dotado de estanques. Esta nueva estancia se adscribe a una remodelación de la casa operada en el siglo II (Cortés 2011: 28, 2014: 123). Por otro lado, aunque solo se conoce una pequeña parte de la domus de la calle Avinyó, su decoración musivaria y parietal (encuadrada dentro del IV estilo) se ha fechado entre la segunda mitad del s. I y el s. II d.C. (Cortés 2011: 36, Beltrán de Heredia y Cortés 2018: 137-156). El opus tessellatum de la habitación 2 se ha datado, justamente, en la fecha de nuestro estudio (Beltrán de Heredia y Cortés 2018: 142-143).

\section{Saguntum}

Tan solo una domus de las excavadas en el antiguo solar de Saguntum entra dentro de nuestros límites cronológicos. Se trata de una vivienda situada en los terrenos del cine Marvi y de la que se han documentado varias estancias (Antoni et al. 2002: 99-116). La construcción de la domus se ha datado en el siglo II, si bien fue ampliamente reformada en una fase posterior, durante el siglo III. Por lo que respecta a su decoración original, destaca el revestimiento pictórico del tablinum, compuesto por imitaciones de crustae de giallo antico (Antoni et al. 2002: 110-111).

\section{Valentia}

La arquitectura doméstica sigue siendo uno de los aspectos menos conocidos del pasado romano de Valentia a pesar de los notables avances que se han dado recientemente (Ribera y Jiménez 2012: 101). Para el periodo que nos ocupa, el mejor ejemplo de vivienda es la llamada casa de Terpsícore, conocida a raíz de las intervenciones desarrolladas en el Palau de les Corts (no obstante, se han planteado otra funciones distintas a la doméstica para esta construcción vid. Escrivá et al. 2016: 428-434). Se trata de un lujosa domus articulada en torno a un atrio y un peristilo. Su construcción se desarrolló en época flavia y, posteriormente, fue reformada en la segunda mitad del siglo II. Especial interés reviste la decoración que presenta la vivienda, en concreto, una exedra cuyo pavimento fue decorado con un gran mosaico, en el que se representó la musa que da nombre a la casa (Jiménez 2006: 479480). Las paredes de la exedra fueron revestidas con un ciclo pictórico de alegorías provinciales, es decir, una serie de figuras femeninas ataviadas con los símbolos más característicos de cada provincia, acompañadas de su nombre en griego dentro de una cartela (fig. 9) (De Hoz 2007: 131-146). Recientemente, se ha excavado una vivienda suburbana en la c/ Purísima. La casa, datada a inicios del siglo II, se sitúa al SO del núcleo urbano, a menos de un kilómetro de las murallas. Estructuralmente está compuesta por una serie de habitaciones, decoradas con mosaicos bícromos con motivos vegetales y geométricos, dispuestas en torno a peristilo trapezoidal (Machancoses y Peñalver 2017: 139-164). Finalmente, cabría indicar que la domus documentada en la plaza de la Almoina quedó amortizada a finales del s. II o inicios del III d.C. (Roselló y Soriano 1998: 43). 


\section{Lucentum}

Solo una de las viviendas conocidas, la domus de la Puerta Oriental, ha arrojado evidencias que se pueden encuadrar dentro del marco temporal de nuestro estudio. La casa se sitúa junto a la torre III del lienzo murario, justo en el sector este de la ciudad (Olcina y Pérez Jiménez 1998: 81). Tras su excavación se comprobó que la residencia presentaba dos fases, a la segunda de las cuales se debe la decoración pictórica de la habitación norte, consistente en una imitación de mármol cipollino y pavonazzetto que cabría datar en época trajano-adrianea (Fernández Díaz 2000-2001: 8-11). Finalmente, la domus fue abandonada en el último cuarto del siglo II (Olcina 2009: 108).

Por otra parte, todo el terreno que delimitaba el núcleo urbano de Lucentum ha sido invadido por construcciones recientes, otorgándonos una visión del yacimiento muy diferente a la que presentaba en época romana. Lógicamente, la construcción de estas edificaciones, llevada a cabo sin control arqueológico alguno, supuso una gran pérdida de información sobre los $s u$ burbia de la ciudad. A pesar de todo, en el hinterland de Lucentum se han podido excavar algunas villae, tanto rurales como suburbanas. La mayor parte de ellas surgieron a inicios de época imperial y su abandono coincide con el momento de declive de la ciudad: el siglo II (Ortega 1999: 471, Olcina 2009: 119-122). Es el caso de la villae de Balsa Finca Castillo y de Casa Ferrer II (Ortega 1999: 471).

\section{Bilbilis}

Los trabajos arqueológicos desarrollados en el yacimiento se han centrado, principalmente, en el estudio del centro monumental. Sin embargo, también se han analizado de forma paralela algunas domus que tuvieron que acomodarse a la abrupta orografía del terreno donde se asienta la ciudad (Martín-Bueno 1991). La información disponible es limitada para el periodo que nos interesa. En la zona meridional del cerro de San Paterno se excavó una vivienda adaptada al sistema de aterrazamiento, puesto que se construyó en dos niveles, uno superior de carácter habitativo y una bodega inferior. La casa, cuya construcción se fecha a inicios del siglo I o principios del II, estuvo decorada con pinturas y presenta una cronología de abandono temprana, siendo deshabitada a finales del siglo II (Martín-Bueno 1991: 174, Guiral y Martín-Bueno 1996: 287-289). En la falda suroriental del cerro de
Bámbola se documentó otra vivienda cuyo aparato decorativo se fecha en el siglo I d.C. y que fue abandonada en la primera mitad de la segunda centuria (Martín-Bueno 1991: 171).

\section{Segobriga}

Las excavaciones y prospecciones desarrolladas en el interior del núcleo urbano no han arrojado testimonios de viviendas en Segobriga. Es decir, todo el área circundada por las murallas estuvo ocupada por edificios públicos y no existen evidencias de construcciones privadas hasta época tardía (Abascal y Cebrián 2007: 543, Abascal y Almagro 2012: 320). Por tanto, habría que pensar que los vecinos residirían en las afueras de la ciudad, ya fuese en viviendas suburbanas o en villae agrícolas. Por otro lado, una gran parte de la población dependió económicamente de la explotación del lapis specularis y, en consecuencia, habitaría en las proximidades de las minas (Abascal y Almagro Gorbea 2012: 320). La única excepción es la domus atribuida al procurador imperial C. Iulius Silvanus. Esta vinculación se deriva del hallazgo en los aledaños de la casa de un altar dedicado por Silvanus a Zeus Theos Megistos. La vivienda se situaba en la zona alta de la ciudad, junto a las termas. De entre las diversas estancias que la componían llama la atención la número 1, espacio consagrado a la citada divinidad de origen griego como santuario particular (Cebrián 2002-2003: 131). En paralelo, destaca la estancia 2, decorada con un rico mosaico y pinturas murales (Abascal y Cebrián 1999: 299, Cebrián y Fernández 2004). Las evidencias arqueológicas coinciden con la cronología propuesta para la inscripción, de forma que esta suntuosa casa debió de erigirse a principios de época severiana (Abascal y Cebrián 1999: 301).

\section{DISCUSIÓN Y CONCLUSIONES}

Como es sabido, la arquitectura doméstica nos brinda información sobre infinidad de aspectos de la vida en las ciudades. Desde el punto de vista de la urbanística, permite analizar el tejido doméstico y el trazado viario; es decir, la distribución planimétrica de una ciudad. Asimismo, el examen de los repertorios ornamentales y de los diferentes ambientes domésticos posibilita evaluar el avance de las modas y determinar el nivel socioeconómico y cultural de los habitantes de 
una determinada comunidad urbana. Igualmente, hay que tener en cuenta que cada casa constituye un microcosmos singular e irrepetible; es decir, un conjunto arquitectónico sujeto a procesos de construcción, transformación, abandono y reutilización (Fernández Vega 1999, Gros 2007: 392-395).

Desde un punto de vista general, el siglo II supuso una época de gran dinamismo para la arquitectura doméstica. Como hemos visto, buena parte de las domus de las ciudades examinadas vivieron en esta etapa intervenciones de distinto signo relacionadas, en su mayor parte, con un aumento del lujo y el bienestar (bien es verdad que nuestro conocimiento es relativo, ya que apenas se conocen las moradas de las capas más bajas de la población hispanorromana). Atendiendo a la documentación arqueológica, podemos concluir que más que un auge de la edificación de nuevas viviendas (que, no obstante y como es natural, se seguirán construyendo), las principales intervenciones en ámbito doméstico se limitaron a ligeras modificaciones en la distribución espacial y actuaciones de orden decorativo.

En efecto, muchas domus de esta época fueron remodeladas arquitectónicamente, lo que conllevó que cambiaran su distribución y asumieran nuevos espacios. En estos casos, es común que la reforma concluya con el embellecimiento de la vivienda. En época antonina, los nuevos ámbitos creados en los domicilios fueron, fundamentalmente, baños domésticos (balnea) y estancias de uso convivial conectadas con jardines para su uso en verano (triclinia aestiva). Del mismo modo, el registro arqueológico revela que una gran proporción de las domus preexistentes se dotaron de nuevos repertorios decorativos en época antonina, especialmente, en la primera mitad de siglo. Entre tales elementos ornamentales destacan: piezas de decoración arquitectónica, pinturas murales del IV estilo, pavimentos marmóreos, así como esculturas domésticas y de jardín (Ramallo 1990: 141-160, Pérez Olmedo 1996: 4249, López Monteagudo 2003: 301-333, Garriguet 2013: 266 y ss., Fernández Díaz 2014: 209-216); elementos y composiciones que demuestran la permeabilidad de las provincias hispanas en lo que respecta a modas estilísticas. En este sentido, los espacios en los que se enfocó la atención fueron perystila-viridiaria, triclinia y, en menor proporción, tablina y oeci; todos ellos ambientes domésticos abiertos a amigos y clientes en los que se proyectaba la riqueza y estatus del dominus (Ellis 1991, Hales 2003: 135 y ss.).

Como se ha dicho, y a pesar de no ser el rasgo distintivo de la arquitectura doméstica, no faltan ejemplos

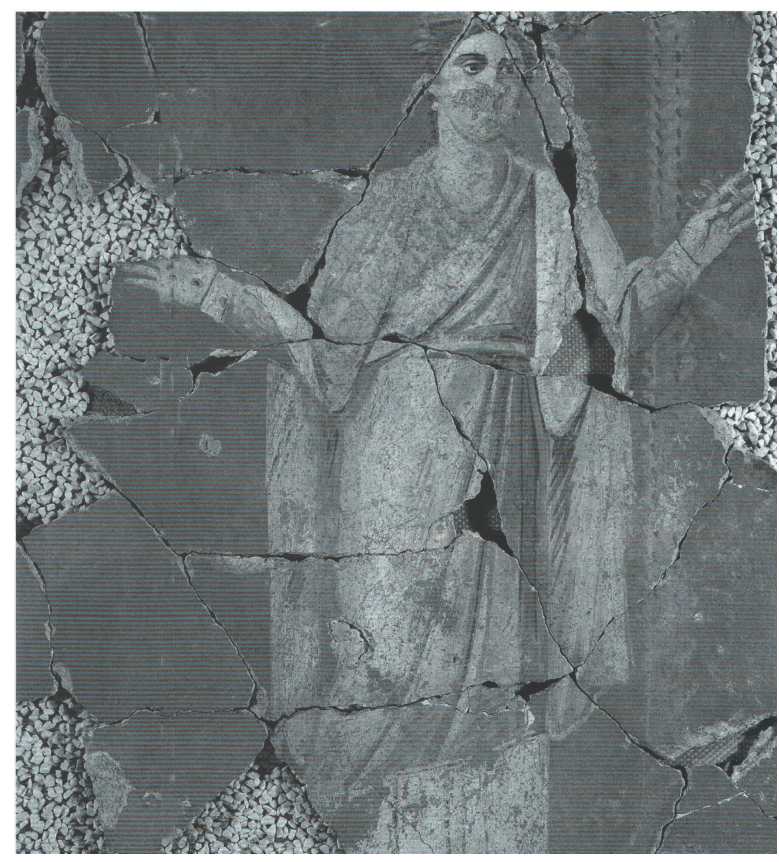

Figura 9. Probable representación de África (a partir de De Hoz 2007: 144, fig. 4).

de casas edificadas en la segunda centuria. Así, la edilicia doméstica de urbes especialmente dinámicas como Astigi, Augusta Emerita, Barcino, Carthago Nova y Munigua comparte un horizonte constructivo común en la primera mitad del siglo II. El modelo de casa imperante en época antonina es la domus de peristilo. $\mathrm{Si}$ bien es cierto que este esquema de vivienda surge en la Hispania de época augustea, será en la segunda centuria cuando desplace definitivamente al modelo de atrio, y continuará siendo predominante durante los siglos III y IV d.C. (Beltrán 2003: 32 y 52, Gros 2001: 148-150, Cortés y Guitart 2011: 45-46, Cortés 2014a: 77-80). Bajo este esquema se articulan diferentes variantes: peristilo porticado concebido como un espacio ajardinado, o bien como espacio abierto sin vegetación; igualmente, también existieron viviendas de peristilo con patios secundarios y viviendas en las que este espacio distribuidor fue el único del hogar (Beltrán 2003: 31). Esta dinámica se registra no solo en Hispania, sino también en la gran mayoría del resto de provincias durante esta etapa (Gros 2001: 148-195, Beltrán 2003: 51 y not. 190). Encontramos excelentes modelos de casas de peristilo de esta cronología en Augusta Emerita, Baetulo, Conimbriga, Valentia y, sobre todo, en Italica. En efecto, la ampliación de esta última ciudad contó con unas domus que representan el mejor y más lujoso ejemplo de vivienda de peristilo de las documentadas 
en Hispania (Gros 2001: 179-184). Se trata de unidades habitacionales de hasta $2.000 \mathrm{~m}^{2}$ de superficie con una fachada porticada en la que, normalmente, se disponen varias tabernas. La distribución interior queda jerarquizada por medio del peristilo, en cuyo eje se abre un triclinium (García y Bellido 1960: 81-102, Luzón 1983: 79 y ss., Mañas 2010: 81-97).

Por otro lado, el siglo II es el momento en el que se difunde el termalismo privado. Por tanto, no extraña que un buen número de domus de esta etapa incorporaran pequeños establecimientos termales; fenómeno que, por otro lado, hay que relacionar con un incremento del grado de confort doméstico (García-Entero 2006: 741744 y 868). De hecho, los baños privados constituyeron un signo de refinamiento y posición económica; ya que, en efecto, mientras que el grueso de la población debía contentarse con acudir a las termas públicas, ciertos privilegiados contaron con balnea en sus propios hogares (Fernández Vega 1999: 218-225). La luxuria que implicaba la posesión de un balneum fue reseñada por varios autores, como es el caso de Séneca (Ep. 86. 7.) y Petronio (Satyr. 73. 2.). Ciertamente, existieron viviendas con ambientes termales desde época republicana, pero no será hasta finales del siglo I d.C. y, sobre todo, durante el siglo II cuando los baños domésticos se conviertan en tendencia en Hispania (García-Entero 2007 2008: 251-254). En el marco cronológico de nuestro estudio, la mayor parte de los balnea se construyeron en residencias preexistentes, por lo que fue necesario amortizar espacios y estancias secundarias de las domus. Generalmente, se ubicaron junto a uno de los pasillos del peristilo de la vivienda y, en menor proporción, en jardines o patios interiores, en una posición menos central (García-Entero 2008: 251-263). Así pues, a la luz del hallazgo de numerosos balnea en ciudades como Augusta Emerita, Barcino, Bracara, Caesar Augusta, Conimbriga y Asturica Augusta, podemos afirmar que la construcción de baños privados constituye uno de los rasgos característicos de las viviendas del siglo II (Fernández Ochoa y García-Entero 2000).

La ampliación de muchas unidades habitacionales se hace a costa de edificar la totalidad de la parcela, amortizando para ello jardines o estancias de servicio. Otras veces, la expansión de la vivienda se lleva a cabo a partir de la compra de terrenos o espacios edificados privados. Hasta aquí nada nuevo; sin embargo, desde el siglo II se registran los primeros casos de extensión de viviendas a costa de espacios públicos. Este fenómeno se ha venido fechando tradicionalmente a partir del siglo III d.C., pero su génesis se encuentra en esta etapa. El ejemplo más evidente se documenta en Augusta Emerita, donde los pórticos de las calles pasaron gradualmente a ser absorbidos por viviendas (Alba 2004: 75). Un caso similar se desarrolló en Barcino, en concreto, la domus localizada en la plaza de Sant Miquel incorporó en el siglo II un conjunto termal, construido, en parte, sobre un kardo minor (Miró 2011: 71-72). Esta dinámica también se detecta en la capital de la Bética, valga como ejemplo la domus de época augustea localizada en plaza Pineda 2. Dicha vivienda fue ampliada en la segunda mitad del siglo II a costa de ocupar la mitad de la extensión de un decumanus minor. Otras veces, como se ha documentado en la intervención de c/ Tomás Conde 8, la invasión por parte de los edificios colindantes provocó, a mediados del siglo II, la reducción de la anchura de una vía (Ruiz Bueno 2014: 46-47, 2015: 102). Esta merma del espacio público, rara antes del siglo II, parece que se relaciona tanto con la falta de superficie edificable en el interior del entramado urbano, como con la relajación de las autoridades en dicha materia. Tal abuso edilicio quedó expresamente prohibido en la legislación y revela, en cierta medida, la prevalencia de la esfera privada sobre la pública, tendencia que no hará más que aumentar con el paso del tiempo (Zaccaria 1995: 260263). Dicha práctica se penaliza de forma expresa en el Edictum perpetuum praetoris urbani, III. De locis et itineribus publicis. Igualmente, en el capítulo XIX de la lex Irnitana se especifica, entre otros aspectos, que era potestad de los ediles la supervisión, limpieza y conservación de las calles, así como la vigilancia de que no hubiera obstáculos que dificultaran el tráfico (cura viarum). En CIL X, 1018 y CIL VI, 266 encontramos dos casos de apropiación de terreno público en época altoimperial por parte de privados recogidos en la epigrafía.

Por último, otro fenómeno que afecta a la arquitectura residencial es el abandono o cambio de uso original. La edilicia doméstica no es ajena a las dificultades que vivieron determinadas comunidades urbanas desde finales del siglo II (Ramallo y Quevedo 2014, Brassous y Quevedo 2015; Andreu 2017). Las huellas materiales de este declive están reflejando un cambio de orden demográfico, económico y político en estas localidades. Esta "decadencia" no solo afectó a las viviendas, puesto que en estas comunidades se detecta no solo falta de intervenciones arquitectónicas, sino también la ausencia de mantenimiento del equipamiento urbano y monumental. Así, el caserío de ciudades como Baetulo, Bilbilis, Carthago Nova y Emporiae, sujeto a los rigores de la crisis económica y demográfica, quedó en buena 
medida abandonado entre la segunda mitad del siglo II y principios del III d.C. (Padrós y Sánchez 2014: 112, Martín-Bueno 2000: 21-22, Vizcaíno 1999: 93, Santos 2012: 83). En estos casos, el tejido urbano fue perdiendo su uniformidad arquitectónica, adquiriendo un estado semirruinoso, de forma que las ciudades acabaron contrayéndose sobre sí mismas (Macías 2012: 72; 2015: 43). La caída de la demografía es difícil de cuantificar con base en registro arqueológico, si bien la amortización de viviendas o su readaptación funcional es un rasgo propio de las ciudades afectadas por la crisis urbana. Hay que subrayar que unos decenios antes de ser abandonados, muchos de estos inmuebles fueron foco de inversión por parte de sus dueños, circunstancia que hace más sorprendente si cabe este fenómeno. No obstante, dicha dinámica no se puede analizar de forma aislada, sino en conjunto con el urbanismo y con las causas y los síntomas de regresión urbana, que pueden ser distintos en función de cada ciudad.

El abandono de viviendas y de sectores urbanos es síntoma de despoblación, como se ha indicado en Emporiae (Nieto 1981: 34-51, Nolla 1993: 212-214, 1998 : 437-439). Sin embargo, no está claro si la caída de la demografía en las ciudades es una consecuencia de la crisis urbana o una causa de la misma. Asimismo, también sería aclarador analizar la evolución del territorio de las ciudades. En este sentido, no existe un patrón común. Por otra parte, la despoblación de las ciudades podría relacionarse con el efecto de la peste antonina (DuncanJones, 1996: 108-136, Scheidel, 2002: 97-114, 2003: 158-176, Bruun, 2003: 426-434). No obstante, no existe en la actualidad ningún tipo de evidencia que autorice a pensar que la enfermedad llegó a las provincias hispanas, si bien sus trazas, en el caso de existir, serían difíciles de reconocer desde el punto de vista arqueológico. Continuando con este asunto, en Carthago Nova y Lucentum el abandono de muchos establecimientos rurales es paralelo a la crisis de la ciudad (Murcia 1999: 231-236, Ortega 1999: 471, Olcina 2009: 119-122). En otras poblaciones, como Iulia Lybica, se ha atestiguado una continuidad en el territorio con respecto a periodos anteriores (Olesti et al. 2014: 72-74). En Baetulo, por su parte, un buen número de villae acogieron remodelaciones arquitectónicas en el siglo II y pasaron a tener una función habitativa (Prevosti 1981: 32). Esto se ha relacionado con un desplazamiento de población del núcleo urbano al territorio (Comas et al. 1999: 4344). También en las villae de la Bética se detectan cambios de tipo arquitectónico y productivo en esta época, transformaciones que están en sintonía con la situación descrita (Fornell 2005).
Todos los fenómenos que venimos comentando se desarrollan, a grandes rasgos, en las tres provincias hispanas. Por tanto, desde el punto de vista territorial, no se observan diferencias notables en las dinámicas globales que afectan a la arquitectura doméstica del siglo II.

Para acabar, cabría hacer una reflexión: en ocasiones se ha hablado de que en época antonina existió un traslado de la inversión a la esfera privada. La naturaleza de nuestro estudio posibilita formular una respuesta al interrogante propuesto. No hace falta que aludamos de nuevo a la traba que supone para ello que las investigaciones se hayan centrado, principalmente, en los espacios y edificios públicos. Por tanto, solo podemos hablar con fundamento de aquellos casos en los que exista un conocimiento firme tanto de la edilicia pública como privada. De esta forma, partiendo de la información arqueológica, es posible afirmar que, en determinados casos, el gasto se concentró de forma preferente en el ámbito doméstico. El caso más evidente lo encontramos en Conimbriga. En efecto, después de la fase de transformación urbana que arranca en época flavia y concluye en época de Trajano, no se ha documentado en el municipio ningún programa constructivo de carácter público. En este sentido, existe más bien un periodo de continuidad y mantenimiento del equipamiento urbano y los espacios monumentales (Correia 2010: 102). Sin embargo, como reflejan las intervenciones efectuadas en las domus de Cantaber, de los Repuxos y de los Esqueletos, los propietarios emplean su patrimonio en la reforma y ampliación de sus suntuosos inmuebles. Otro caso análogo lo encontramos en Emporiae, donde el pulso de la edilicia pública -dejando al margen las termas- es mínimo. Esta comunidad se encuentra en franca regresión desde época flavia y su foro se halla en estado ruinoso desde el inicio del siglo II (Castanyer et al. 1993, Nolla 1993: 1998). No obstante, en esta misma época las casas 1 y $2 \mathrm{~B}$ fueron ampliamente reformadas e incorporaron nuevos espacios, conformando, de esta forma, viviendas con una extensión de $3.000 \mathrm{~m}^{2}$. Aunque existen menos evidencias, esta misma dinámica parece imperar en Barcino y Caesar Augusta. En la segunda se han constatado solo algunas actividades constructivas y decorativas en espacios públicos, pero en el campo de la arquitectura doméstica se advierte, en cambio, un verdadero dinamismo (Casabona y Pérez Casas 1991: 22, Beltrán 1993: 104-106). Muestra de ello son los numerosos pavimentos musivos fechados en este siglo y las refinadas esculturas domésticas encuadradas dentro del clasicismo adrianeo. Por su parte, las intervenciones en la próspera Barcino 
de época antonina también se encauzaron mayoritariamente en el ámbito privado (Rodà 2001: 22-33, Beltrán de Heredia 2010: 31-41).

En síntesis, la arquitectura doméstica es un campo especialmente activo en la segunda centuria. Atendiendo al registro arqueológico de las ciudades analizadas, la mayor parte de las actuaciones consisten en cambios en la distribución espacial, así como en la renovación del aparato decorativo de viviendas de cronología anterior al siglo II, aunque no faltan ejemplos de construcción de nuevas domus. En relación con esto, la atención se focalizó, especialmente, en peristilos y triclinios, como demuestra la gran cantidad de pavimentos musivos fechados en época antonina que decoraban estos espacios de representación. Otro de los rasgos característicos de la edilicia doméstica de este siglo es la construcción de baños privados en los inmuebles, en línea con la luxuria privata y con el interés por las termas públicas que caracteriza este periodo. Ello estaría manifestando, en buena medida, que durante la segunda centuria la inversión de los particulares se trasladó al ámbito doméstico. En efecto, esta es la tónica que impera en Barcino, Caesar Augusta, Conimbriga o Emporiae, ciudades en las cuales el gasto se concentró, preferentemente, en la reforma y ampliación de suntuosas domus frente al mantenimiento del cuadro monumental público heredado del siglo anterior.

\section{Agradecimientos}

El resultado de nuestra investigación se ha beneficiado del apoyo financiero del Programa Estatal de Promoción del Talento y su Empleabilidad, en el marco del Plan Estatal de Investigación Científica y Técnica y de Innovación 2013-2016, entre las que se encuentran las ayudas Juan de la Cierva-formación 2016 (FJCI-201629310).

\section{BIBLIOGRAFÍA}

A.A.V.V. (1991): La casa urbana hispanorromana. Ponencias y comunicaciones. Zaragoza, Institución Fernando el Católico.

Abad, L. (1982): La pintura romana en España. Alicante, Universidad de Alicante.

Abascal, J.M. y Almagro Gorbea, M. (2012): "Segobriga, la ciudad hispano-romana del sur de la Celtiberia", en G. Carrasco (coord.), La ciudad romana en Castilla-La Mancha: 287-370. Cuenca, Universidad de Castilla-La Mancha.

Abascal, J.M. y Cebrián, R. (1999): "Mosaico romano de Segobriga". Archivo Español de Arqueología 72: 299-301, doi: <http://dx.doi.org/10.7203/SAGVNTVM..1861>.

Abascal, J.M. y Cebrián, R. (2007): "Las murallas romanas de Segobriga", en A. Rodríguez Colmenero e I. Rodá (eds.), Murallas de ciudades romanas en el occidente del Imperio: Lucus Augusti como paradigma: 527-546. Lugo, Diputación Provincial de Lugo.

Adserias, A.; Pociña, C.A. y Remolà, J.A. (2000): "L'habitat suburbá al sector afectat pel PERI-2 (Jaume I, Tabacalera)". en J. Ruiz de Arbulo (ed.), Tarraco 99: arqueologia d'una capital provincial romana: 137-154. Tarragona, Universitat Rovira i Virgili.

Alarcão, J. (2010): As casas da zona B de Conimbriga. Coimbra, Centro de Estudos Arqueológicos das Universidades de Coimbra e Porto.

Alba, M. (2004): "Arquitectura doméstica", en X. Dupré (ed.), Las capitales provinciales de Hispania, Mérida, Colonia Augusta Emerita: 67-83. Roma, L'Erma di Bretschneider.

Álvarez Martínez, J.M. y Nogales, T. (2011): "Las producciones pictóricas y musivas emeritenses", en J.M. Álvarez Martínez y P. Mateos (eds.), 19102010, el yacimiento emeritense: 463-490. Mérida, Museo Nacional de Arte Romano.

Andreu, J. (2014): "Rationes rei publicae uexatae y oppida labentia: la crisis urbana de los siglos II y III d. C. a la luz del caso del municipio de Los Bañales de Uncastillo (Zaragoza, España)", en D. Vaquerizo, J.A. Garriguet y A. León (eds.), Ciudad $y$ territorio: transformaciones materiales e ideológicas entre la época clásica y el Altomedioevo: 251-264. Córdoba, Universidad de Córdoba.

Andreu, J. (ed.) (2015): Oppida labentia. transformaciones, cambios y alteración en las ciudades hispanas entre el siglo II y la tardoantigüedad. Uncastillo, Fundación Uncastillo.

Antoni, C.; Hernández, F.J. y De Antonio, J.M. (2002): "Noticia preliminar de las excavaciones de la domus romana del solar del cinema Marvi (Sagunt)". Arse 36: 99-116.

Arasa, F. (2009): La ciutat romana de Lesera. Forcall, Ajuntament de Forcall, disponible en $<$ http://roderic.uv.es/handle/10550/34623>.

Arévalo, A. y Bernal, D. (2007): "Síntesis y perspectivas de investigación”, en A. Arévalo y D. Bernal 
(coords.), Las cetariae de Baelo Claudia. Avance de las investigaciones arqueológicas en el barrio meridional (2000-2004): 547-556. Sevilla, Junta de Andalucía.

Balil, A. (1972): Casa y urbanismo en España antigua. Valladolid, Universidad de Valladolid.

Barata, M.F. (1998): Mirobriga: urbanismo e arquitectura. Lisboa, Ministério da Cultura.

Barata, M.F. (1999): “As habitaçoes de Mirobriga e os ritos domésticos romanos". Revista Portuguesa de Arqueologia 2, 2: 51-68.

Beltrán de Heredia, J. (2010): "Barcino de colonia augustea a sede regia en época visigoda. Las transformaciones urbanas a la luz de las nuevas aportaciones de la arqueología", en Arqueología, patrimonio y desarrollo urbano. Problemática y soluciones: 31-49. Girona, Ajuntament de Girona.

Beltrán, A. (1952): "Una casa romana en Zaragoza", en Actas del II Congreso Nacional de Arqueología: 439-50. Zaragoza, Institución Fernando el Católico.

Beltrán, M. (1993): "El teatro de Caesaragusta. Estado actual del conocimiento". Cuadernos de arquitectura romana 2: 93-118.

Beltrán, M. (2003): "La casa hispanorromana. Modelos". Bolskan 20: 13-63, disponible en <http://revistas.iea.es/index.php/BLK/article/view/451>.

Beltrán, M. y Fatás, G. (1998): Historia de Zaragoza. Cesar Augusta ciudad romana. Zaragoza, Ayuntamiento de Zaragoza.

Beltrán, M. y Mostalac, A. (1996): “La casa romana en Hispania. Estado de la cuestión", en La maison urbaine d'epoque romaine en Gaule narbonnaise et dans les provinces voisines: 61-71. Vaucluse, Service d'Archéologie du Conseil Général de Vauclus.

Beltrán, M. y Mostalac, A. (2007): “Arquitectura doméstica”, en F. Beltrán (ed.), Las capitales provinciales de Hispania, Zaragoza, Colonia Caesar Augusta: 71-84. Roma, L'Erma di Bretschneider.

Beltrán, M.; Mostalac A., Paz J. y Aguarod M.C. (1985): "La Arqueología urbana en Zaragoza", en Arqueología de las ciudades modernas superpuestas a las antiguas: 73-116. Madrid, Ministerio de Cultura.

Berlanga, M. y Melero, F. (2009): “Cartima a través de las fuentes arqueológicas y epigráficas”, en J. González y P. Pavón (eds.), Andalucía romana y visigoda. Ordenación y vertebración del territorio: 167-190. Roma, L'Erma di Bretschneider.

Bermejo Meléndez, J. (2011): "El fin del modelo urbano y municipal en Arucci Turobriga: la transformación hacia la antigüedad tardía (ss. III-VII d.C.)".
Arqueología y territorio medieval 18: 55-70, doi: $<$ https://dx.doi.org/10.17561/aytm.v18i0.1467>.

Bermejo Tirado, J. (2014): Arqueología de los espacios domésticos romanos: Condiciones de vida y sociedad en la Meseta nordeste durante el período imperial. Soria, Diputación Provincial de Soria.

Bernal D., Arévalo, A.; Aguilera, L.; Lorenzo, L.; Díaz, J. J. y Expósito J.A. (2007a): "La topografía del barrio industrial. Baelo Claudia, paradigma de la industria conservera urbana hispanorromana", en A. Arévalo y D. Bernal (coords.). Las cetariae de Baelo Claudia. Avance de las investigaciones arqueológicas en el barrio meridional (2000-2004): 91-212. Sevilla, Junta de Andalucía.

Bernal D.; Arévalo, A.; Lorenzo L. y A. Cánovas (2007b): "Abandonos en algunas insulae del barrio industrial a finales del siglo II d.C.”, en A. Arévalo y D. Bernal (coords.), Las cetariae de Baelo Claudia. Avance de las investigaciones arqueológicas en el barrio meridional (2000-2004): 383-451. Sevilla, Junta de Andalucía.

Betrán de Heredia, J. y Cortés, A. (2018): “La domus de la calle Avinyó de Barcelona: un ejemplo de la arquitectura doméstica de las elites barcinonenses en los siglos I-II". Anales de Arqueología Cordobesa 29: 137-156, disponible en $<$ http://hdl.handle. net/10396/17735>

Bonneville, J.N.; Dardaine, S. y Le Roux, P. (1988): L'epigraphie: les incriptions romaines de Baelo Claudia. Paris, Diffusion De Boccard.

Brassous, L. y Quevedo, A. (eds.) (2015): Urbanisme civique en temps de crise. Les espaces publics d'Hispanie et de l'Occident romain entre le IIe et le IVe siècle. Madrid, Casa de Velázquez.

Bruun, C. (2003): "The Antonine Plague in Rome and Ostia". Journal of Roman Archeology 16: 426-434, doi: <https://doi.org/10.1017/ S1047759400013234>.

Burón, M. (1997): El trazado urbano en las proximidades del foro en Asturica Augusta: la Casa del pavimento de Opus Signinum. Valladolid, Junta de Castilla y León.

Burón, M. (2002): "El proceso urbanizador en Asturica Augusta: las primeras construcciones domésticas", en L. Hernández Buena; L. Sagredo y J.M. Solana (eds.), Actas del I Congreso Internacional de Historia Antigua "La Península Ibérica hace 2000 años”: 263-268. Valladolid, Universidad de Valladolid.

Canovas, A. (2010): "La arquitectura doméstica de la zona occidental de Colonia Patricia Corduba", en 
D. Vaquerizo y J.F. Murillo (eds.), El anfiteatro romano de Córdoba y su entorno urbano. Análisis arqueológico (ss. I-III d.C.): 415-427. Córdoba, Universidad de Córdoba.

Canto, A. (1976): "El mosaico del Nacimiento de Venus de Itálica”. Habis 7: 293-338, disponible en $<$ http://hdl.handle.net/11441/29145>.

Carrasco, I. y Romero Paredes, C. (2001): "Intervención arqueológica de urgencia en la plaza de Giles y Rubio $n^{\circ} 9$ esquina a C/ bodegas, a C/ Berbisa y a plaza de Giles y Rubio n ${ }^{\circ} 19$ de Écija, Sevilla”. Anuario Arqueológico de Andalucía 1997, 3: 576-579.

Carrillo, J.R. (1999): "Evolución de la arquitectura doméstica en Colonia Patricia Corduba", en F.R. García Verdugo y F. Acosta (coords.), Córdoba en la Historia. La construcción de la Urbe: 75-86. Córdoba, Ayuntamiento de Córdoba.

Casabona, J.I. y Pérez Casas, J.A. (1991): “El fórum de Caesaragusta", en Zaragoza, prehistoria y arqueología: pp. 17-26. Zaragoza, Ayuntamiento de Zaragoza.

Castanyer, P.; Sanmartí, E.; Santos, M.; Tremoleda, J.; Benet, C.; Carreté, J.M.; Fàbrega, X.; Remolá, J.A. y Rocas, X. (1993): “L'excavació del kardo B. Noves aportacions sobre l'abandonement de la ciutat romana d'Empuries". Cypsela 10: 159-194, disponible en <https://www.raco.cat/index.php/Cypsela/ article/view/119175>.

Cebrián, R. (2002-2003): "Surtidor de fuente procedente de la vivienda de C. Iulius Silvanus en Segóbriga (Saélices, Cuenca, Conventus Carthaginesis)". Lucentum 21-22: 131-134, doi: <https://doi. org/10.14198/LVCENTVM2002-2003.21-22.08>.

Cebrián, R. y Fernández, A. (2004): “Un techo pintado en la domus de G. lulius Siluanus en Segobriga (Saelices, Cuenca. Conventus Carthaginensis)", en Plafonds et voutes a l'époque antique, Actes du Vllle. Colloque International de l'Association Internationale pour la Peinture Múrale Antique: pp. 137-146. Budapest, Pytheas Kft.

Comas, M.; Guitart, J. y Padrós, J. (1999): "Prehistòria i Història Antiga", en J. Villarroya (dir.). Història de Badalona: 21-52. Badalona, Editorial Base.

Corrales, A. (2016): La arquitectura doméstica de Augusta Emerita. Madrid, CSIC.

Correia, V.H. (2001): "Conimbriga, casa atribuida a Cantaber. Trabalhos arqueológicos 1995-1998”. Conimbriga 40: 83-140.

Correia, V.H. (2004): “Coexistência e revoluçao. Urbanismo e arquitectura em Conimbriga (séc. I
a.C.-III d.C.)", en M.C. Lopes y R. Vilaça (coords.), O passado em cena: narrativas e fragmentos. Miscelânea oferecida a Jorge de Alarçao: 261-298. Coimbra, Centro de Estudos Arqueológicos.

Correia, V.H. (2010a): “O fórum de Conimbriga e a evoluçao do centro urbano”, en T. Nogales (coord.), Ciudad y foro en Lusitania romana: 89-106. Mérida, Museo Nacional de Arte Romano.

Correia, V.H. (2010b): Arquitectura domestica de Conimbriga e as estructuras económicas e sociais da cidade romana. Tesis Doctoral, Universidade de Coimbra. Inédita, disponible en $<$ http://hdl.handle. net/10316/18134>.

Correia, V.H. (2013): A arquitectura doméstica de Conimbriga e as estructuras económica e sociais da cidade romana. Coimbra, Centro de Estudos Arqueológicos das Universidades de Coimbra e Porto.

Correia, V.H. (2017): A arquitetura do ocidente da Lusitânia romana: entre o público e o privado. Lisboa, Academia das Ciências de Lisboa, disponible en $<$ https://comum.rcaap.pt/handle/10400.26/19489>.

Correia, V.H. y Reis, M.P. (2000): “As termas de Conimbriga: tipologías arquitectónicas e integraçao urbana", en C. Fernández Ochoa y V. García-Entero (eds.), Termas romanas en el Occidente del Imperio: 271-280. Gijón, VTP.

Cortés, A. (2009): "L'arquitectura domèstica a Tarraco. Epoca tardorepublicana i altimperial". Butlletí Arqueologic 31: 511-534, disponible en $<$ https://www.raco.cat/index.php/ButlletiArq/article/view/314883>.

Cortés, A. (2011): "L'arquitectura doméstica de la ciutat romana de Barcino". Quaderns d'Arqueologia $i$ Història de la Ciutat de Barcelona 7: 16-66.

Cortés, A. (2014a): “Clasificación tipológica de la arquitectura doméstica romana. Reflexiones a partir de las ciudades del NE peninsular". Pyrenae 45, 2: 59-93, disponible en $<$ https://www.raco.cat/index. php/Pyrenae/article/view/286121>.

Cortés, A. (2014b): L'arquitectura domèstica d'època tardorepublicana $i$ altimperial a les ciutats romanes de Catalunya. Barcelona, Institut d'Estudis Catalans.

Cortés, A. y Guitart, J. (2011): "La Arqueología de la casa romana en Cataluña". Bollettino di Archeologia on line. Proceedings of the XVII International Congress of Classical Archaeology, vol. esp.: 34-49.

Cuyàs, J.M. (1977): Historia de Badalona. Badalona Romana i visigòtica. Badalona, Arts Grafiques Duran. 
De Hoz, M.P. (2007): “A new set of simulacra gentium indenified by greek inscriptions in the so called house of Terpsichore in Valentia (Spain)". Zeitschrift für Papyrologie und Epigraphik 163: 131-146.

De Palol, P. (1994): Clunia. Historia de la ciudad y guía de las excavaciones. Burgos, Diputación Provincial de Burgos.

Didierjean, F.; Ney, C. y Paillet, J.L. (1986): Le macellum. Paris, Diffusion De Boccard.

Duncan-Jones, R. (1996): "The impact of the Antonine plague". Journal of Roman Archeology 9: 108-136, doi: <https://doi.org/10.1017/ S1047759400016524>.

Egea, A.; Ruiz, E. y Vizcaíno, J. (2011): "Carthago Nova”, en J.A. Remolá y J. Acero (eds.), La gestión de los residuos urbanos en Hispania: 281-296. Mérida, CSIC.

Ellis, S.P. (1991): "Power, architecture and decor: how the Late Roman aristocrat appeared to his guest", en E.K. Gazda (ed.), Roman Art in private sphere: 117134. Michigan, The University of Michigan Press.

Escrivá, M.J.; Jiménez, J.L.; Machancoses, M. y Ribera, A. (2016): "Domus de Terpsicore, Valentia (Valencia)", en O. Rodríguez Gutiérrez; N. Tran y B. Soler Huertas (coords.), Los espacios de reunión de las asociaciones romanas: 428-434. Sevilla, Universidad de Sevilla.

Fernández Díaz, A. (2000-2001): “Algunos restos pictóricos de la ciudad de Lucentum (Tossal de Manises-Alicante)". Lucentum 1920: 215-236, doi: <https://doi.org/10.14198/ LVCENTVM2000-2001.19-20.14>.

Fernández Díaz, A. (2014): "La evolución de los centros urbanos en Hispania a través de su pintura mural (s. II-IV d.C.)", en S.F. Ramallo y A. Quevedo (eds.), Las ciudades de la Tarraconense oriental entre los s. II-IV d.C. Evolución urbanística y contextos materiales: 207-244. Murcia, Universidad de Murcia.

Fernández Díaz, A. y Quevedo, A. (2008): "La configuración de la arquitectura doméstica en Carthago Nova desde la época tardo-republicana hasta los inicios del Bajoimperio". Anales de prehistoria y arqueología 23-24: 273-309, disponible en $<$ https:// revistas.um.es/apa/article/view/178131>.

Fernández Díaz, A. y Suárez, L. (2006): "La Gorgona/Medusa en el pavimento de una domus de la ciudad de Carthago Nova: un unicum en un conjunto de mosaicos geométricos y bícromos". Anales de prehistoria y arqueología 22: 73-108, disponible en $<$ https://revistas.um.es/apa/article/ view/93171/125371>.

Fernández Díaz, A. (2017): "La pintura mural romana en los ambientes domésticos", en E. Ruiz Valderas (coord.), Cartagena, Colonia Urbs Julia Nova Carthago: 79-82. Roma, L'Erma di Bretschneider.

Fernández Díaz, A.; Murcia, A. y García, C. (2005): “Actuación arqueológica en C/ Beatas (Cartagena): constatación de una nueva técnica decorativa en ámbito doméstico". Anales de prehistoria y arqueología 21: 127-146, disponible en <https://revistas. um.es/apa/article/view/93071/0>.

Fernández Ochoa, C. y García-Entero, V. (eds.) (2000): Termas romanas en el Occidente del Imperio. Gijón, VTP.

Fernández Vega, P.A. (1999): La casa romana. Madrid, Akal.

Fornell, A. (2005): "Evolución de las villae béticas durante la dinastía Antonina”, en L. Hernández (ed.), La Hispania de los Antoninos (98-180): 587-596. Valladolid, Universidad de Valladolid.

García Marcos, V. y Vidal, J.M. (1993): Astorga. Excavaciones y restos arqueológicos. León, La Crónica 16.

García Marcos, V. y Vidal, J.M. (1996): “Asturica Augusta: recientes investigaciones sobre su implantación y desarrollo urbano", en C. Fernández Ochoa (coord.), Los finisterres atlánticos en la Antigüedad: 135-145. Madrid, Electa.

García Marcos, V. y Vidal, J.M. (1999): “Asturica Augusta: de asentamiento militar a urbs magnifica”, en A. Rodríguez Colmenero (coord.), Los orígenes de la ciudad en el noreste hispánico, vol. II: 911-944. Lugo, Diputación Provincial de Lugo.

García Villalba, C. y Sáenz Preciado, J. (2015): “Municipium Augusta Bilbilis ¿paradigma de la crisis de la ciudad julio-claudia?", en L. Brassous y A. Quevedo (eds.), Urbanisme civique en temps de crise. Les espaces publics d'Hispanie et de l'Occident romain entre le IIe et le IVe siècle: 221-235. Madrid, Casa de Velázquez.

García-Dils, S. (2015): Colonia Augusta Firma Astigi. El urbanismo de la Écija romana y tardoantigua. Sevilla, Universidad de Sevilla.

García-Dils, S.; Ordóñez, S. y Rodríguez Gutiérrez, O. (2009): "La casa del Oscillum en Astigi: Aspectos edilicios", en R. Cruz-Auñón y E. Ferrer (coords.), Estudios de Prehistoria y Arqueología en homenaje a Pilar Acosta Martínez: 521-544. Sevilla, Universidad de Sevilla.

García-Dils, S.; Ordóñez, S.; Conlin, E.; Saquete, J.C. y Sáez, P. (2006): "La casa de las Hermae de Astigi”. 
Habis 37: 349-364, disponible en <https://hdl. handle.net/11441/72378>.

García-Dils, S.; Ordóñez, S.; Sánchez Velasco, J.; Vázquez, J. y Fournier, J. (2011): "La conversión de una porticus monumental de colonia Augusta Firma en recinto funerario cristiano". Habis 42: 263-291, disponible en $<$ http://hdl.handle.net/11441/12170>.

García-Entero, V. (2006): Los balnea domésticos -ámbito rural y urbano- en la Hispania romana. Madrid, CSIC.

García-Entero, V. (2008): “El ocio en el ámbito doméstico de la arquitectura hispanorromana: las termas". Anales de prehistoria y arqueología 23-24: 253272, disponible en $<$ https://revistas.um.es/apa/article/view/178121>

Garriguet, J.A. (2013): “La ornamentación escultórica de la Bética entre Trajano y Antonino Pío. Breves reflexiones sobre su producción e importación”, en R. Hidalgo y P. León (eds.), Roma, Tibur, Baetica. Investigaciones adrianeas: 251-269. Sevilla, Universidad de Sevilla.

Gros, P. (2001): L'Architecture romaine. Maisons, palais, villas et tombeaux. Paris, Diffusion De Boccard.

Gros, P. (2007): Storia dell'urbanistica. Il mondo romano. Roma, Laterza.

Guilabert, A.; Olcina, M. y Tendero, E. (2015): “Lucentum (Tossal de Manises, Alicante). Estudio de caso de un municipium de la Tarraconense sur", en L. Brassous y A. Quevedo (eds.), Urbanisme civique en temps de crise. Les espaces publics d'Hispanie et de l'Occident romain entre le IIe et le IVe siècle: 145-160. Madrid, Casa de Velázquez.

Guiral, C. (2015): "Un conjunto de estucos de la Colonia Caesar Augusta", en M. Salvadori; A. Didonè y G. Salvo (eds.), TECT 2: la pittura frammentaria di età romana, metodi di catalogazione e studio dei reperti: 123-137. Padova, Padova University Press.

Guiral, C. y Martín-Bueno, M. (1996): Bilbilis I: decoración pictórica y estucos ornamentales. Zaragoza, Institución Fernando El Católico.

Guitart, J. (1976): Baetulo: topografía arqueológica, urbanismo e historia. Badalona, Ayuntamiento de Badalona.

Guitart, J.; Padrós, P. y Puerta, C. (1991): "La casa urbana en Baetulo", en La casa urbana hispanorromana. Ponencias y comunicaciones: 35-47. Zaragoza, Institución Fernando el Católico.

Gutiérrez Behemerid, M.A. (2002): La decoración arquitectónica en la Colonia Clunia Sulpicia. Valladolid, Universidad de Valladolid.
Hales, S. (2003): The roman house and social identity. Cambridge, Cambridge University Press.

Hauschild T. (1985): "Munigua. Informe preliminar sobre las excavaciones en casa 1 y casa 6 (Campaña de 1982)". Noticiario Arqueológico Hispánico 23: 235-267.

Hauschild T. y Haussmann E. (1991): “Casas romanas de Munigua", en La casa urbana hispanorromana. Ponencias y comunicaciones: 329-335. Zaragoza, Institución Fernando el Católico.

Járrega, R.; Diloli, J.; Ferré, R. y Vilà, J. (2014): “Elementos urbanísticos de abandono y una posible crisis estructural en la ciudad de Dertosa (Hispania Citerior) en el siglo II d.C.", en S.F. Ramallo y A. Quevedo (eds.), Las ciudades de la Tarraconense oriental entre los s. II-IV d.C. Evolución urbanistica y contextos materiales: 149-174. Murcia, Universidad de Murcia.

Jiménez, J.L. (2006): “Consideraciones sobre la evolución de las corrientes decorativas en la ciudad romana de Valentia", en D. Vaquerizo y J.F. Murillo (coords.), El concepto de lo provincial en el mundo antiguo: 471-484. Córdoba, Universidad de Córdoba.

Keay, S. (2004): "El territorio", en X. Dupré (ed.), Tarragona: Colonia Iulia Urbs Triumphalis Tarraco. Las capitales provinciales de Hispania 3: 97-109. Roma, L'Erma di Bretschneider.

Koppel, E.M. (1985): Die römischen Skulpturen von Tarraco. Berlin, Walter de Gruyter.

Koppel, E.M. y Rodá, I. (2007): "La escultura”, en F. Beltrán (ed.), Las capitales provinciales de Hispania 4, Zaragoza, Colonia Caesar Augusta: 109-122. Roma, L'Erma di Bretschneider.

López Monteagudo, G. (2003): "Mosaicos hispanos de época de Trajano", en J. Alvar y M. Blázquez (eds.), El Imperio de Trajano: 301-333. Madrid, Universidad Complutense.

Machancoses, M. y T. Peñalver (2017): “Purísima 3: un ambiente doméstico periurbano en Valentia”. Cuadernos de Arqueología de la Universidad de Navarra 25: 139-164, disponible en <http://hdl.handle. net/10171/45803>.

Macias, J.M. (2001): "La villa romana de la Llosa en el marc de l'ocupació agricola del territorium de Tàrraco", en M. García; J.M. Macias; J. Menchon; J.M. Puche; E. Ramón y J.A. Remolà (eds.), La villa romana de la LLosa. Deus anys d'investigació arqueológica: 40-50. Cambrils, Ajuntament de Cambrils.

Macias, J.M. (2004): "Arquitectura doméstica", en X. Dupré (ed.). Tarragona: Colonia Iulia Urbs 
Triumphalis Tarraco. Las capitales provinciales de Hispania 3: 73-95. Roma, L'Erma di Bretschneider.

Macias, J.M.; Fiz, I.; Piñol, L.; Miró, M.T. y Guitart, J. (2007): Planimetria arqueològica de Tàrraco. Tarragona, Institut Català d'Arqueologia Clàssica.

Macias, J.M. y Puche, J.M. (1997): "Noves excavacions a la part baixa de Tarragona. Dades per a l'evolució urbanística de la ciutat romana". Tribuna d'Arqueologia 1995-1996: 149-163, disponible en $<$ http://hdl.handle.net/10687/91603>.

Madrid, M.J. (2004): "Primeros avances sobre la evolución urbana del sector oriental de Carthago Nova. PERI CA-4/ Barrio universitario". Mastia 3: 31-70.

Madrid, M.J. (2017): "La arquitectura doméstica", en E. Ruiz Valderas (coord.), Cartagena, Colonia Urbs Julia Nova Carthago: 69-78. Roma, L'Erma di Bretschneider.

Magalhães, F. (2010): Arquitectura doméstica em Bracara Augusta. Tesis Doctoral, Universidade do Minho. Inédita disponible en $<\mathrm{http}$ :/hdl.handle. net/1822/13619>.

Mañas, I. (2009): "Pavimentos decorativos de Itálica. Una fuente para el estudio de la ampliación adrianea". Romula 8: 179-199, disponible en <https://www.upo. es/revistas/index.php/romula/article/view/209>.

Mañas, I. (2010): “Arquitectura doméstica", en A. Caballos (ed.), Itálica-Santiponce, Municipium y Colonia Aelia Augusta Italicensium: 81-97. Roma, L'Erma di Bretschneider.

Mañas, I. (2011): Mosaicos romanos de Itálica (II): mosaicos contextualizados y apéndice. Madrid, CSIC.

Mar, R. y Ruiz de Arbulo, J. (1993): Ampurias romana. Historia, arquitectura y arqueología. Sabadell, AUSA.

Mar, R.; Ruiz de Arbulo, J.; Vivó, D. y Beltrán-Caballero, J.A. (2012): Tarraco. Arquitectura y urbanismo de una capital provincial romana. De la Tarragona ibérica a la construcción del templo de Augusto. Tarragona, Universitat Rovira i Virgili.

Márquez, C. (1993): Capiteles romanos de Corduba Colonia Patricia. Córdoba, Monte de Piedad y Caja de Ahorros de Córdoba.

Márquez, C. (2005): "Córdoba romana: dos décadas de investigación arqueológica", Mainake 27: 33-60.

Márquez, J. (2010): "Los suburbios de Augusta Emerita en perspectiva diacrónica", en D. Vaquerizo (ed.), Las áreas suburbanas en la ciudad histórica. Topografía, usos, función: 135-152. Córdoba, Universidad de Córdoba.

Martín, M.; Ortiz, D.; Portí, M. y Vidal, M. (2001): “La domus de la Fortuna: un conjunto arquitectónico doméstico de época romana en la calle del Duque", en E. Ruiz y M. Martínez Andreu (coords.), La casa romana en Carthago Nova. Arquitectura privada y programas decorativos: 19-52. Murcia, Tabularium.

Martín-Bueno, M. (1991): "Bilbilis: arquitectura doméstica", en La casa urbana hispanorromana. Ponencias y comunicaciones: 165-180. Zaragoza, Institución Fernándo el Católico.

Martín-Bueno, M. (2000): Bilbilis Augusta. Zaragoza, Caja de Ahorros de la Inmaculada de Aragón.

Martins, M. (1997-1998): “A zona arqueológica das Carvalheiras. Balanço das escavações e interpretação do conjunto". Cadernos de Arqueologia 14-15: 23-46, disponible en <http://hdl.handle. net/1822/10409>.

Martins, M. (2009): "Bracara Augusta: panorama e estado da questao sobre o seu urbanismo", en M. Dopico; M. Villanueva y P. Rodríguez (eds.), Do castro a cidade: a romanización na Gallaecia e na Hispania indoeuropea: 181-212. Lugo, Diputación Provincial de Lugo.

Meyer, K.; Basas, C. y Teichner, F. (2001): Mulva IV: die Hauser 1 und 6, la cerámica de la casa n. 6, das Haus 2. Mainz am Rhein, Von Zabern.

Miró, C. (2011): "Els balnea de les domus de Barcino". Quaderns d'Arqueologia i Història de la Ciutat de Barcelona 7: 68-83.

Morand, I. (2005): La maison aux Jets d'eau de Conimbriga (Portugal). Programmes architectural et décoratif. Paris, Diffusion De Boccard.

Morena, J.A.; Ventura, A.; Márquez, C. y Moreno, A. (2011): "El foro de la ciudad romana de Torreparedones (Baena, Córdoba): primeros resultados de la investigación arqueológica (Campaña 20092010)", Itálica 1: 145-169.

Moreno González, M.F. (1996): Aproximación al estudio de la decoración musivaria en Colonia Patricia Corduba. Córdoba, Universidad de Córdoba.

Murcia, A.J. (1999): "Poblamiento rural romano en el Campo de Cartagena: el tránsito de los siglos II al III d.C. ", en Actas del XXIV Congreso Nacional de Arqueología, vol. IV: 231-236. Cartagena, Instituto de Patrimonio Histórico.

Nieto Prieto, J. (1981): “Acerca del progresivo despoblamiento de Ampurias". Rivista di Studi Liguri 47: 34-51.

Noguera, J.M. (2002a): "Carthago Nova: una metrópoli hispana del Mediterráneo occidental”, en J.M. Abascal; J.M. Noguera y F. González (eds.), Cartagena romana. Historia y epigrafía. Edición facsímil 
y estudio de Inscripciones de carthago Nova, hoy Cartagena, en el reyno de Murcia, ilustradas por el excelentísimo señor Conde Lumiares, individuo de la Academia de Ciencias y Artes de Padua: 49-87. Murcia, Tabularium.

Noguera, J.M. (2002b): "Un edificio del centro monumental de Carthago Nova: análisis arquitectónicodecorativo e hipótesis interpretativas". Journal of Roman Archaeology 15: 63-96, doi: <https://doi. org/10.1017/S1047759400013842>.

Nolla, J.M. (1993): “Ampurias en la Antigüedad tardía. Una nueva perspectiva”. Archivo Español de Arqueología 66: 207-224, doi: <https://doi. org/10.3989/aespa.1993.v66.470>.

Nolla, J.M. (1998): "Empuries. Creiximent, crisis i adaptació. Algunes consideracions", en M. Mayer; J.M. Nolla y J. Pardo (eds.), De les estructures indigenes a l'organització provincial romana de la Hispania citerior: 429-439. Barcelona, Institut d'Estudis Catalans.

Olcina, M. (ed.) (2009): Lucentum (Tossal de Manises, Alicante): arqueología e historia. Alicante, Museo Arqueológico de Alicante.

Olcina, M. y Pérez Jiménez, R. (1998): La ciudad ibero-romana de Lucentum (El Tossal de Manises, Alicante). Introducción a la investigación del yacimiento arqueológico y su recuperación como espacio público. Alicante, Museo Arqueológico de Alicante.

Olesti, O.; Guàrdia, J. y Mercadal, O. (2014): “El fin del sueño urbano en Iulia Livica (Llívia, Cerdaña)", en S.F. Ramallo y A. Quevedo (eds.), Las ciudades de la Tarraconense oriental entre los s. II-IV d.C. Evolución urbanística y contextos materiales: 6188. Murcia, Editum.

Ortega, J.R. (1999): “Aportaciones al estudio del poblamiento romano en el entorno de Lucentum (Alicante)", en XXIV Congreso Nacional de Arqueología, vol. IV: 467-474. Murcia, Instituto de Patrimonio Histórico.

Padrós, P. y Sánchez, J. (2014): “Transformaciones en los espacios urbanos en Baetulo. Siglos II al IV d.C.", en S.F. Ramallo y A. Quevedo (eds.), Las ciudades de la Tarraconense oriental entre los siglos II-IV d.C.: 89-118. Murcia, Editum.

Palma, F. (1997): "Las casas romanas intramuros en Mérida. Estado de la cuestión". Mérida excavaciones arqueológicas, 3: 347-365.

Paz, J.A. (1991): Cerámica de mesa romana de los siglos III al VI d.C. en la provincia de Zaragoza. Zaragoza, Institución Fernando el Católico.
Peña, A. (2010): Estudio de la decoración arquitectónica romana y análisis del reaprovechamiento del material en la Mezquita Aljama de Córdoba. Córdoba, Universidad de Córdoba.

Peña, A. (2011): "La escultura doméstica", en M.D. Baena; C. Márquez y D. Vaquerizo (comis.), Córdoba reflejo de Roma: 146-155. Córdoba, Ayuntamiento de Córdoba.

Pérez González, C.; Illarregui, E. y Arribas, P. (2015): "Tiermes en los siglos II-IV. Evolución del poblamiento y del urbanismo de una ciudad de la cuenca del Duero", en S.F. Ramallo y A. Quevedo (eds.), Las ciudades de la Tarraconense oriental entre los s. II-IV d.C. Evolución urbanística y contextos materiales: 237-251. Murcia, Editum.

Pérez Maestro, C. (2005): "Nuevas aportaciones para el conocimiento de la secuencia ocupacional del área periurbana de Mérida". Mérida excavaciones arqueológicas 8: 227-246.

Pérez Olmedo, E. (1996): Revestimientos de opus sectile en la Península Ibérica. Valladolid, Universidad de Valladolid.

Perich, A. (2014): "Las transformaciones urbanas en Tarraco. El ámbito doméstico a finales del altoimperio", en S.F. Ramallo y A. Quevedo (eds.), Las ciudades de la Tarraconense oriental entre los s. IIIV d.C. Evolución urbanística y contextos materiales: 119-147. Murcia, Editum.

Prevosti, M. (1981): Cronologia i poblament a l'area rural de Baetulo. Badalona, Museu de Badalona.

Quevedo, A. y Ramallo, S.F. (2015): “La dinámica evolutiva de Carthago Nova entre los siglos II y III", en L. Brassous y A. Quevedo (eds.), Urbanisme civique en temps de crise. Les espaces publics d'Hispanie et de l'Occident romain entre le IIe et le IVe siècle: 161-177. Madrid, Casa de Velázquez.

Ramallo, S.F. (1990): “Talleres y escuelas musivas en la Península Ibérica", en Mosaicos romanos. Estudios sobre iconografia: 135-180. Guadalajara, Asociación Española del Mosaico.

Ramallo, S.F. (2006): “Talleres urbanos y talleres locales en los capiteles corintios de Cartagena" en D. Vaquerizo y J.F. Murillo (eds.), El concepto de lo provincial en el mundo antiguo, vol. I: 451-470. Córdoba, Universidad de Córdoba.

Ramallo, S.F. y Quevedo, A. (eds.) (2014): Las ciudades de la Tarraconense oriental entre los s. IIIV d.C. Evolución urbanística y contextos materiales. Murcia, Editum.

Ramallo, S.F. y Vizcaíno, J. (2007): "Evolución del sistema defensivo de Cartagena durante la Antigüedad", 
en A. Rodríguez Colmenero e I. Rodà (coords.), $M u$ rallas de Ciudades Romanas en el Occidente del Impero. Lucus Augusti como paradigma: 483-522. Lugo, Diputación Provincial de Lugo.

Regueras, F. (1991): "Mosaicos romanos de Asturica Augusta". Boletín del Seminario de estudios de arte y arqueología 57: 131-162.

Reis, M.P. y Correia, V.H. (2006): "Jardins de Conimbriga: arquitetura e gestao hidrulica”, en J.P. Morel; J. Tressera y J.C. Matamala (eds.), The archeology of cropfields and gardens: 293-312. Bari, Edipuglia.

Reis, M.P.; De Man, A. y Correia, V.H. (2011): “Conimbriga", en J. Acero y J.A. Remolá, (eds.), $L a$ gestión de los residuos urbanos en Hispania: 181202. Mérida, CSIC.

Ribeiro, J. y Martins, M. (2013): “Os procesos constructivos da edilicia privada em Bracara Augusta: o caso da Domus das Carvalheiras", en A. Sousa y M. Carmo (coords.), Historia da construçao, arquitecturas e tecnicas construtivas: 75-98. Braga, CITCEM.

Ribera, A. y Jiménez, J.C. (2012): "Valentia, ciudad romana: su evidencia arqueológica", en J. Beltrán y O. Rodríguez Gutiérrez (coords.), Hispaniae Urbes. Investigaciones arqueológicas en ciudades históricas: 77-120. Sevilla, Universidad de Sevilla.

Rodá, I. (2001): "Barcelona. Desde su fundación hasta el siglo IV d.C.”, en J. Beltrán de Heredia (dir.), De Barcino a Barcinona (siglos I-VII). Los restos arqueológicos de la plaza del Rey de Barcelona: 2231. Barcelona, Ajuntament de Barcelona.

Rodríguez Gómez, A. (2010): La arquitectura doméstica urbana en época romana en la provincia Baetica. Tesis Doctoral, Universidad de Huelva. Inédita, disponible en $<$ http://hdl.handle.net/10272/2870>.

Rodríguez Termiño, I. (1991): "La casa urbana hispanorromana en Augusta Firma Astigi, Écija, Sevilla", en La casa urbana hispanorromana. Ponencias y comunicaciones: 345-354". Zaragoza, Institución Fernando el Católico.

Roldán, L. (1991): "La casa de la Exedra de Itálica (Santiponce, Sevilla). Un intento de valoración espacial a través de las técnicas constructivas", en $L a$ casa urbana hispanorromana. Ponencias y comunicaciones: 303-311. Zaragoza, Institución Fernando el Católico.

Romero Vera, D. (2014): "Dinámicas urbanas en el siglo II d.C.: el caso de Colonia Augusta Firma Astigi (Écija, Sevilla)". en D. Vaquerizo, J.A. Garriguet y A. León (eds.), Ciudad y territorio: transformaciones materiales e ideológicas entre la época clásica y el Altomedioevo: 217-234. Córdoba, Universidad de Córdoba.

Romero Vera, D. (2016): La ciudad hispanorromana en el s. II d.C. Consolidación y transformación de un modelo urbano. Tesis Doctoral, Universidad de Córdoba. Inédita, disponible en $<$ http://hdl.handle. net/10396/14222>.

Rosselló, M. y Soriano, R. (1998): "Los restos arqueológicos exhibidos", en Cripta arqueológica de la Cárcel de San Vicente: 41-56. Valencia, Ajuntament de València.

Ruiz Bueno, M.D. (2014): "El entorno del decumanus maximus de Colonia Patricia: ¿evidencia de una remodelación urbanística hacia época severiana?", en D. Vaquerizo, J.A. Garriguet y A. León (eds.), Ciudad y territorio: transformaciones materiales e ideológicas entre la época clásica y el Altomedioevo: 41-54. Córdoba, Universidad de Córdoba.

Ruiz Bueno, M.D. (2015): "El kardo maximus de Córdoba en la Antigüedad Tardía". Anales de Arqueología Cordobesa 25-26: 83-114, doi: <https://doi. org/10.21071/aac.v0i25-26.6416>.

Ruiz Bueno, M.D. (2018): Dinámicas topográficas urbanas en Hispania. El espacio intramuros entre los siglos II y VII d.C. Bari, Edipuglia.

Ruiz Valderas, E. (1996): "Los niveles de abandono del siglo II d. C. en Cartagena: los contextos de la calle Jara n ${ }^{\circ} 12$ ", en Actas del XXIII Congreso Nacional de Arqueología, vol. I: 503-514. Elche, Ayuntamiento de Elche.

Sáez, P.; Ordóñez, S.; García Vargas, E. y García-Dils, S. (2004): Carta Arqueológica Municipal de Écija. 1. La ciudad. Sevilla, Junta de Andalucía.

Santos, M. (1991): "Distribución y evolución de la vivienda urbana tardorrepublicana y altoimperial en Ampurias", en La casa urbana hispanorromana. Ponencias y comunicaciones: 19-34. Zaragoza, Institución Fernando el Católico.

Santos, M. (2012): “Arquitectura doméstica", en X. Aquilué (ed.). Empuries, Municipium Emporiae: 69-84. Roma, L'Erma di Bretschneider.

Schattner, T.G. (2003): Munigua: cuarenta años de investigaciones. Sevilla, Junta de Andalucía.

Scheidel, W. (2002): "A model for demographic and economic change in Roman Egypt after the Antonine plague". Journal of Roman Archeology 15: 97-114, doi: <https://doi.org/10.1017/ S1047759400013854>.

Scheidel, W. (2003): "Germs for Rome", en C. Edwards and G. Woolf (eds.), Rome the cosmopolis: 158-176. Cambridge, Cambridge University Press. 
Secilla, R. y Márquez, C. (1991): “Una casa romana en el S.E. de Colonia Patricia Corduba: un ejemplo a seguir". en La casa urbana hispanorromana. Ponencias y comunicaciones: 337-342. Zaragoza, Institución Fernando el Católico.

Sillières, P. (1991): "La maison romaine a Baelo Claudia. Essai de révision de donnes anciennnes", en $L a$ casa urbana hispanorromana. Ponencias y comunicaciones: 321-326. Zaragoza, Institución Fernando el Católico.

Sillières, P. (1997): Baelo Claudia: una ciudad romana de la Bética. Madrid, Casa de Velázquez.

Sillières, P.; Magallón, M.A. y Navarro, M. (1995): “El municipium Labitolosanum y sus notables: novedades arqueológicas y epigráficas". Archivo Español de Arqueología 68: 107-130, doi: <https://doi. org/10.3989/aespa.1995.v68.400>.

Soler, B. (2003): "Algunas consideraciones sobre el empleo privado del mármol en Carthago Nova". Mastia 2: 149-187.

Soler, B. (2005): "Hacia una sistematización cronológica sobre el empleo del marmor y su comercialización en Carthago Nova". Mastia 4: 29-64.

Soler, B. (2017): "Pavimentos en opus sectile y otros revestimientos marmóreos en la arquitectura doméstica", en E. Ruiz Valderas (coord.), Cartagena, Colonia Urbs Julia Nova Carthago: 83-85. Roma, L'Erma di Bretschneider.
Teichner, F.; Oberhofer, K. y Kopf, J. (2014): "Miróbriga (Santiago do Cacém, Portogallo): nuovi dati archeologici sul modello lusitano della residenza privata in età romana", en J.M. Álvarez; T. Nogales y I. Rodà (eds.), XVIII CIAC: Centro y periferia en el mundo clásico: 1121-1124. Mérida, Museo Nacional de Arte Romano.

Uribe, P. (2015): La arquitectura doméstica urbana romana en el Valle Medio del Ebro (Siglos II a.C.III d.C.). Bordeaux, Aquitania Supplément.

Vaquerizo, D. (2004): “Arquitectura doméstica y funeraria”, en X. Dupré, (ed.), Las capitales provinciales de Hispania. Córdoba. Colonia Patricia Corduba: 81-94. Roma, L'Erma di Bretschneider.

Vegas, M. (1985): "Munigua. Casa 6. Estudio de los materiales para fechar las habitaciones y el pozo". Noticiario Arqueológico Hispánico 23: 269-289.

Vera, E.; Romero Paredes, C. y Carrasco, I. (2005): “Intervención arqueológica de urgencia realizada en un solar sito en la calle Avendaño número 7. Écija. Sevilla". Anuario Arqueológico de Andalucía 2002, 3: 487-498.

Vizcaíno, J. (1999): “Transformaciones del urbanismo tardoantiguo en Cartagena. El caso de los vertederos". Anales de prehistoria y arqueología 14: 8798, disponible en $<\mathrm{https}$ ://revistas.um.es/apa/article/view/62351>.

Zaccaria, A. (1995): Spazio privato e spazio pubblico nella città romana. Roma, Ecole française de Rome. 